\title{
AIR-SIDE PERFORMANCE OF RVACS/RACS--DESCRIPTION OF THE NATURAL CONVECTION SHUTDOWN HEAT REMOVAL \\ TEST FACILITY AND SUPPORTING ANALYSIS
}

by

T. T. Anderson, C. August, N. J. Carson, 0. D. Despe, H. J. Haupt, J. B. Heineman, M. R. Kraimer, P. A. Lottes, H. J. Myers, J. R. Pavlik, D. R. Pedersen, G. J. Pokorny, R. R. Stewart, and J. H. Tessier

\author{
Reactor Analysis and Safety Division \\ Argonne National Laboratory \\ 9700 South Cass Avenue \\ Argonne, Illino is 60439
}

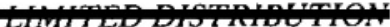

Tho-TM-aries provides the documentation of results for the ANL tasks perfommet

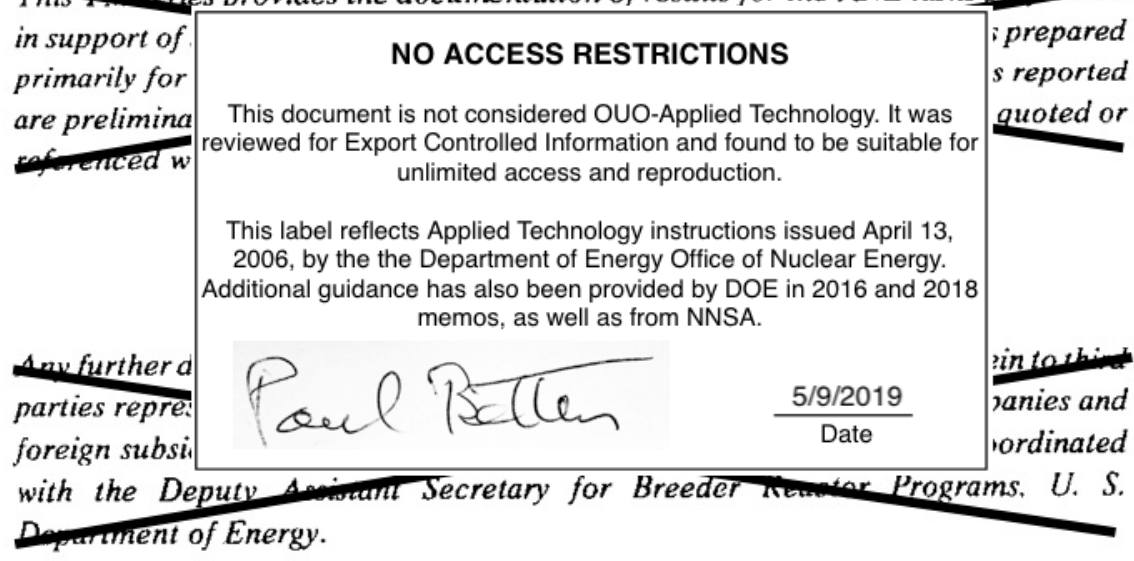




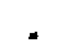




\section{TABLE OF CONTENTS}

\section{$\underline{\text { Page }}$}

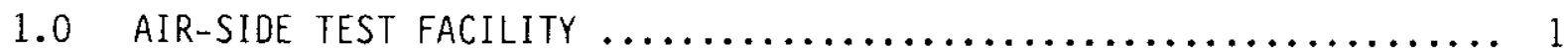

1.1 Segment Test - Mechanical Systems $\ldots \ldots \ldots \ldots \ldots \ldots \ldots \ldots \ldots \ldots$

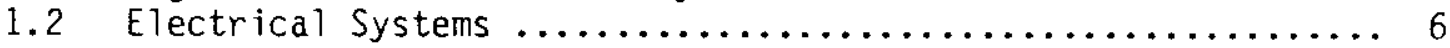

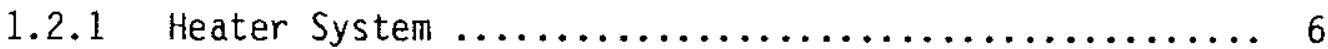

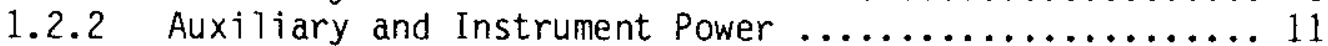

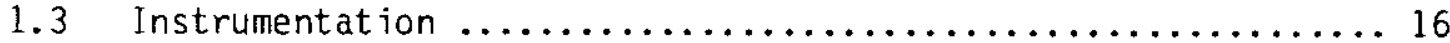

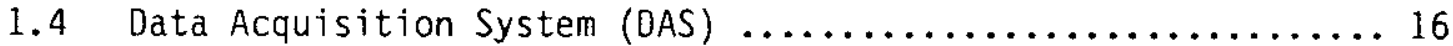

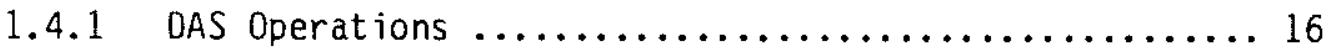

1.4.2 DAS Software - Completed Activities ................ 19

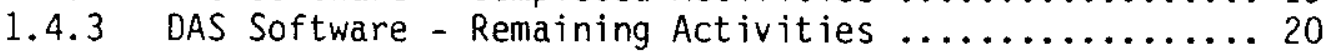

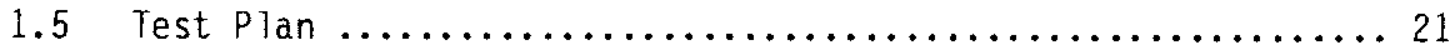

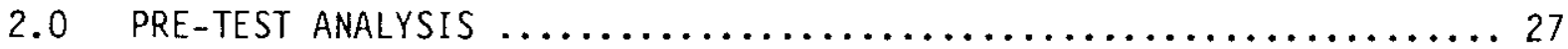

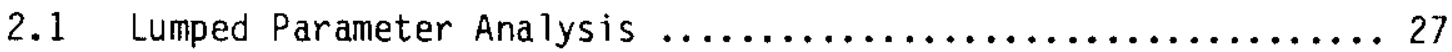

2.1.1 Model Development $\ldots \ldots \ldots \ldots \ldots \ldots \ldots \ldots \ldots \ldots \ldots \ldots \ldots \ldots$

2.1.2 Calculated RVACS Test Assembly Performance ......... 32

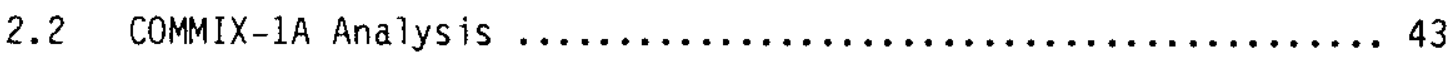

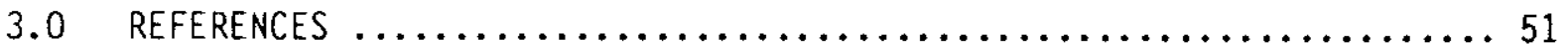

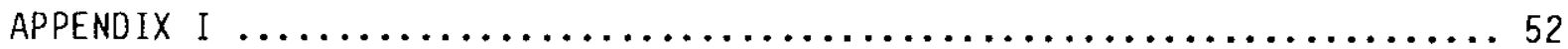




\section{LIST OF FIGURES}

Page

1. Aerial View - Building 310 Area $\ldots \ldots \ldots \ldots \ldots \ldots \ldots \ldots \ldots \ldots \ldots$

2. Test Assembly Configuration $\ldots \ldots \ldots \ldots \ldots \ldots \ldots \ldots \ldots \ldots \ldots$

3. Mechanical Design and Fabrication Status $\ldots \ldots \ldots \ldots \ldots \ldots \ldots \ldots$

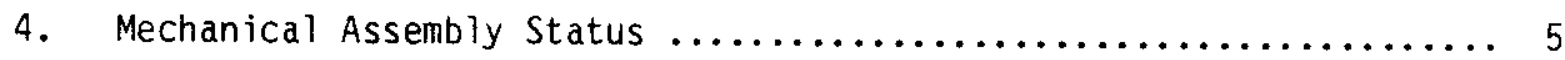

5. Test Section in Place $\ldots \ldots \ldots \ldots \ldots \ldots \ldots \ldots \ldots \ldots \ldots \ldots \ldots \ldots$

6. Upper Test Section in Place $\ldots \ldots \ldots \ldots \ldots \ldots \ldots \ldots \ldots \ldots \ldots \ldots$

7. RVACS Heater Control and DAS System $\ldots \ldots \ldots \ldots \ldots \ldots \ldots \ldots \ldots$

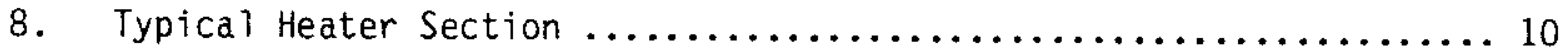

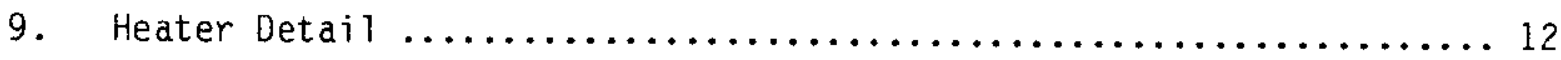

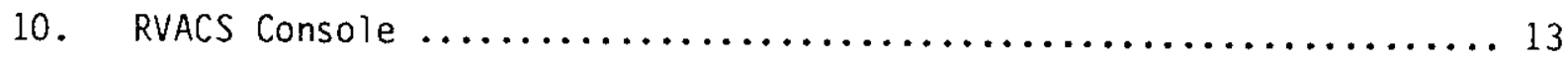

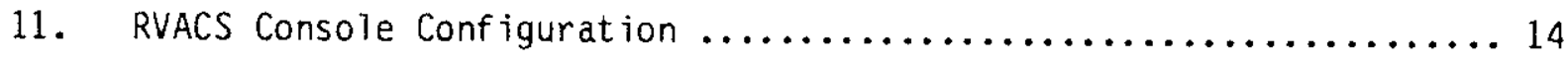

12. Electrical Control System Block Diagram RVACS/RACS ........... 18

13. Test Assembly Performance Map $\ldots \ldots \ldots \ldots \ldots \ldots \ldots \ldots \ldots \ldots \ldots$

14. Performance for Guard Vessel Temperature $=900^{\circ} \mathrm{F} \ldots \ldots \ldots \ldots$

15. Effect of Guard Vesse1 to Collector Gap Size on Guard

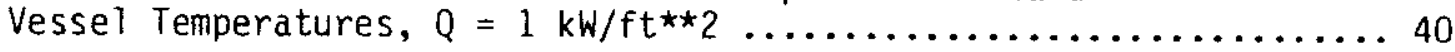

16. Effect of Guard Vessel to Collector Gap Size on Air Velocity,

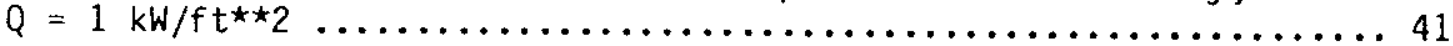

17. Effect of Guard Vessel to Collector Gap Size on Relative

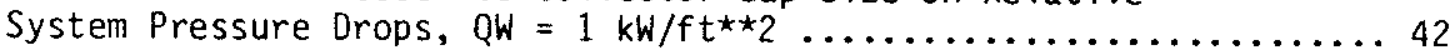

18. Air Velocity Channeling in RVACS $U=5 \mathrm{M} / \mathrm{S}, \mathrm{Q}=0 \mathrm{KW} / \mathrm{M} \star \star 2$, $\mathrm{MUT} / \mathrm{MU}=100 \quad 45$

19. Velocity Profiles for Symmetric Heating $\ldots \ldots \ldots \ldots \ldots \ldots \ldots \ldots$

20. Turbulent Kinetic Energy for Symmetric Heating $\ldots \ldots \ldots \ldots \ldots \ldots \ldots 4$

21. RVACS Velocity Profile at Exit $U=5 \mathrm{M} / \mathrm{S}, Q=0.0$,

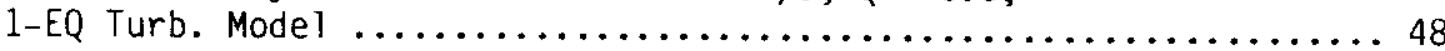

22. RVACS Turb. Kinetic Energy Profile at Exit $U=5 \mathrm{M} / \mathrm{S}, Q=0.0$, 1 EQ Turb. Model 


\section{LIST OF TABLES}

Page

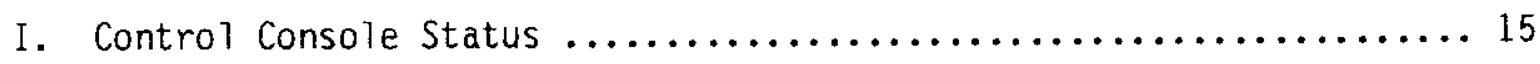

II. Instrumentation Requirements $-\operatorname{RVACS} \ldots \ldots \ldots \ldots \ldots \ldots \ldots \ldots \ldots$

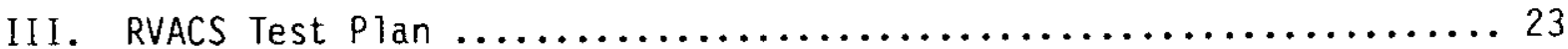

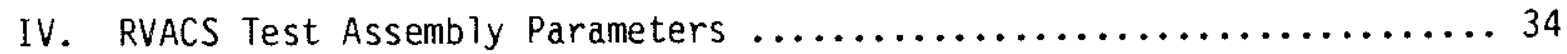

V. RVACS LoSS Coefficients for GE Simulation $\ldots \ldots \ldots \ldots \ldots \ldots \ldots \ldots$

VI. Estimated Loss Coefficient for ELGO Weather Cap ............. 36

VII. Pretest Parametrics for the RVACS PRISM Experiments ........... 39 


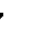




\section{AIR-SIDE PERFORMANCE OF RVACS/RACS-DESCRIPTION OF \\ THE NATURAL CONVECTION SHUTDOWN HEAT REMOVAL TEST FACILITY AND SUPPORTING ANALYSIS}

by

T. T. Anderson, C. August, N. J. Carson, 0. D. Despe, H. J. Haupt, J. B. Heineman, M. R. Kraimer, P. A. Lottes, H. J. Myers, J. R. Pavlik, D. R. Pedersen, G. J. Pokorny, R. R. Stewart, and J. H. Tessier

\section{ABSTRACT}

This report contains a description of the construction/ fabrication status of the Natural Convection Shutdown Heat Removal Test Facility as of July 1986 and the concomittant pre-test analysis for the PRISM/RVACS (Radiant Vessel Auxiliary Cooling System) configuration installed for the initial experiments. Also included is the initial test plan and contingent test phases. The current schedule anticipates initial power operations in late October. (Since this report was issued in draft form in July, construction has been completed and experiment operations began in November 1986). 
viji 


\subsection{AIR-SIDE TEST FACILITY}

This section describes the current status of the ANL out-of-pile experiment test assembly that simulates the GE Radiant Vessel Auxiliary Cooling System (RVACS). This description is an update of the design and fabrication/assembly status presented in reference 1 .

The RVACS air-side experiments will be carried out at ANL in Building 310, a facility which provides the required high-bay capability for the full-scale simulation of the guard vessel/collector geometries typical of LMR pool-type designs. Figure 1 is an aerial view of the ANL "300" area, looking northeast. Indicated is the location of Building 310 and also shown is the location of externals pertinent to RVACS, i.e., the exhaust (hot-air) stack, and the meteorological tower. Neither is in place to date.

The Test Assembly is comprised of a structural model, electric heaters, instrumentation, insulation, and a computerized control and data acquisition system. Experiment operation will simulate prototypic reactor vessel temperatures, air flow patterns, and heat removal conditions that would exist for a RVACS system during normal reactor operation and/or a shutdown situation. In general, the system will operate in either of two thermal modes: (1) constant guard vessel wall temperature to $1000^{\circ} \mathrm{F}$ or (2) constant heat flux to $2.0 \mathrm{~kW} / \mathrm{ft}^{2}$. In addition, the system will accommodate stepwise variation of either mode singly or in combination.

\subsection{Segment Test - Mechanical Systems}

Figure 2 illustrates the basic assembly configuration and salient features. A major design change for more prototypic stack effect has been incorporated as shown, i.e., addition of an "S" section and a vertical run and weather cap to approximately $50 \mathrm{ft}$. above the previous design of the air flow exit (see reference 1). Figures 3 and 4 show the current status of test assembly mechanical design, fabrication, procurement, and in-place assembly.

Major activities completed in the past several months are as follows: 


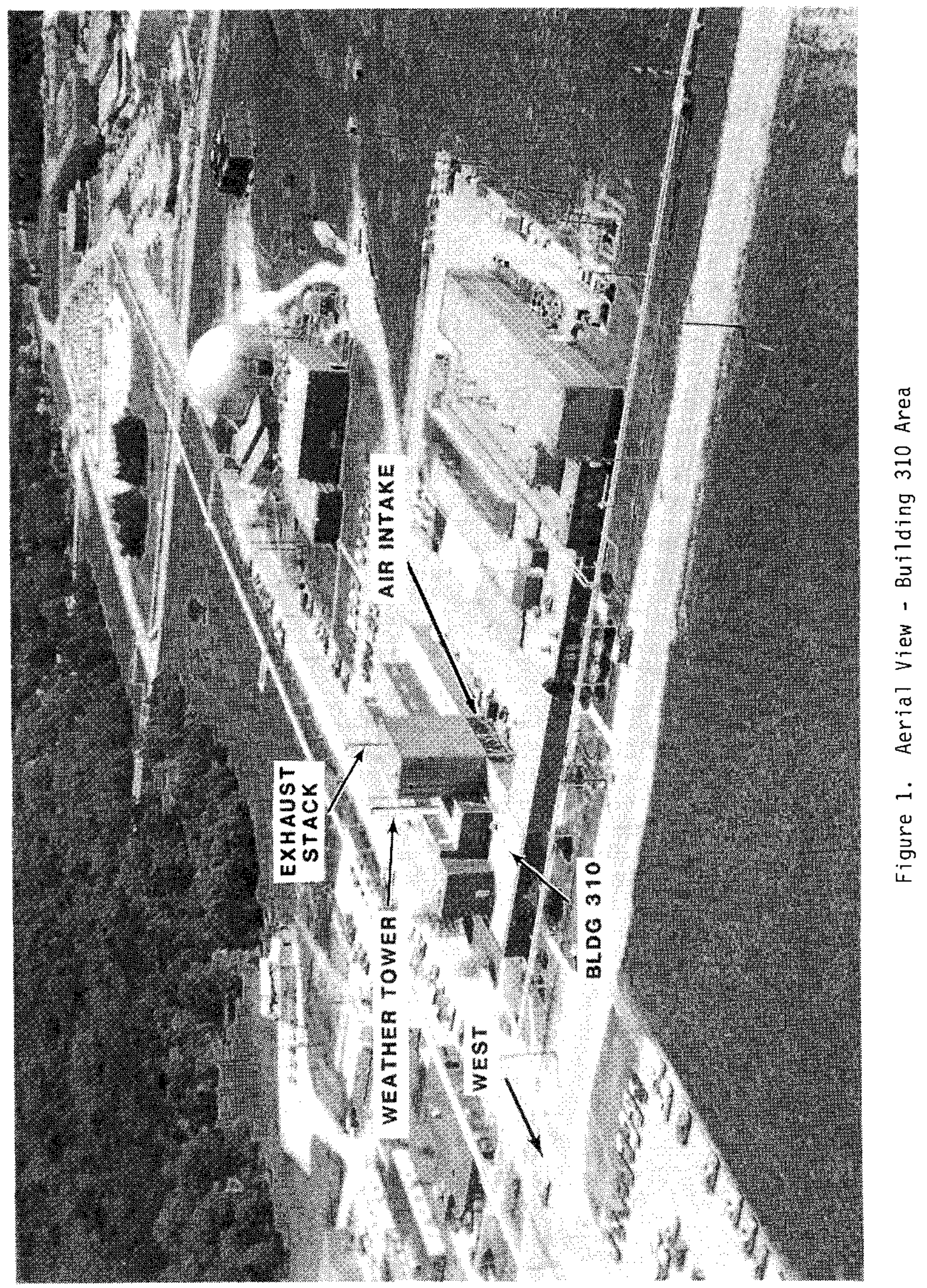




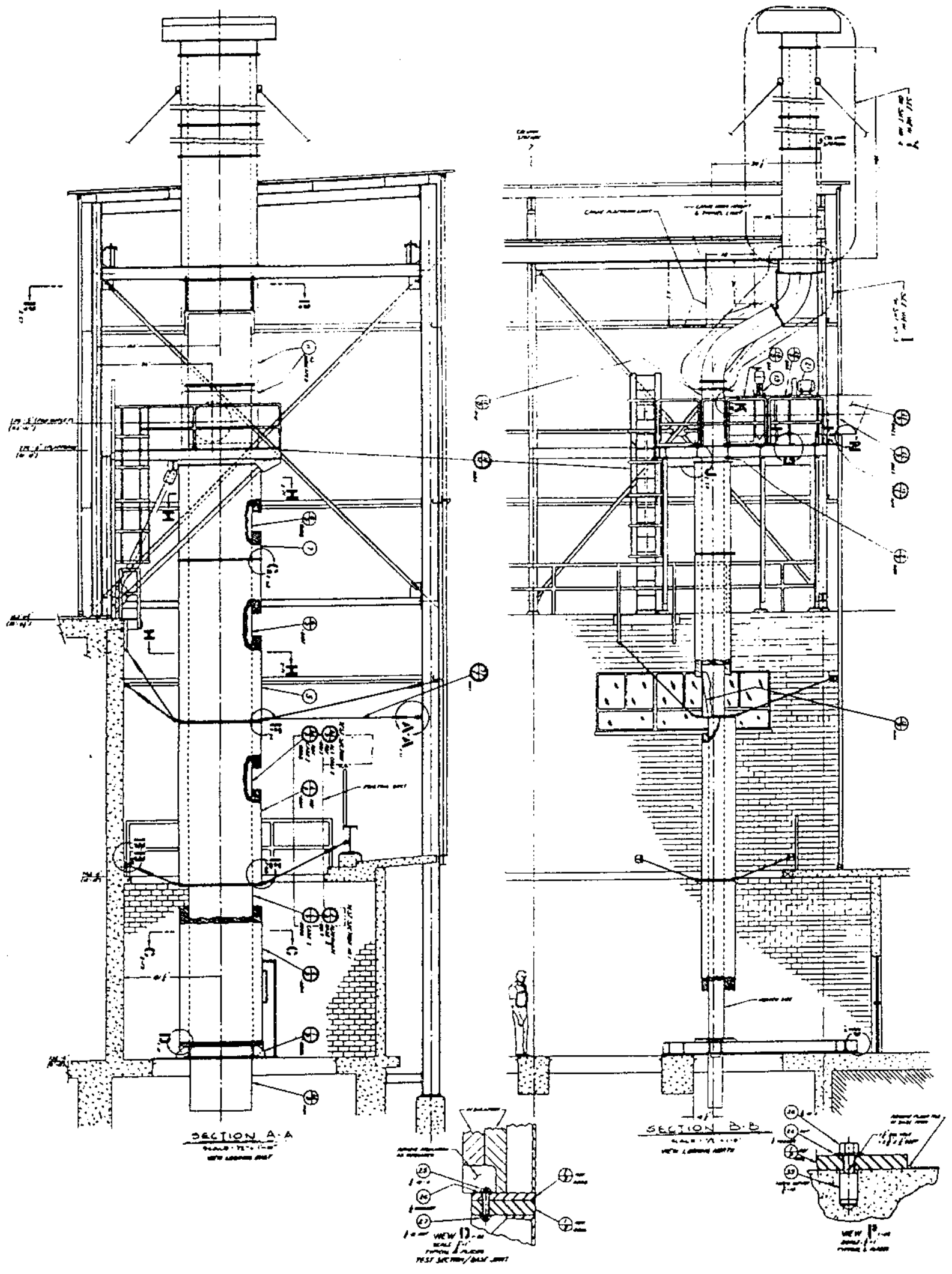

Figure 2. Test Assembly Configuration 
$-4-$

$7 / 25 / 86$

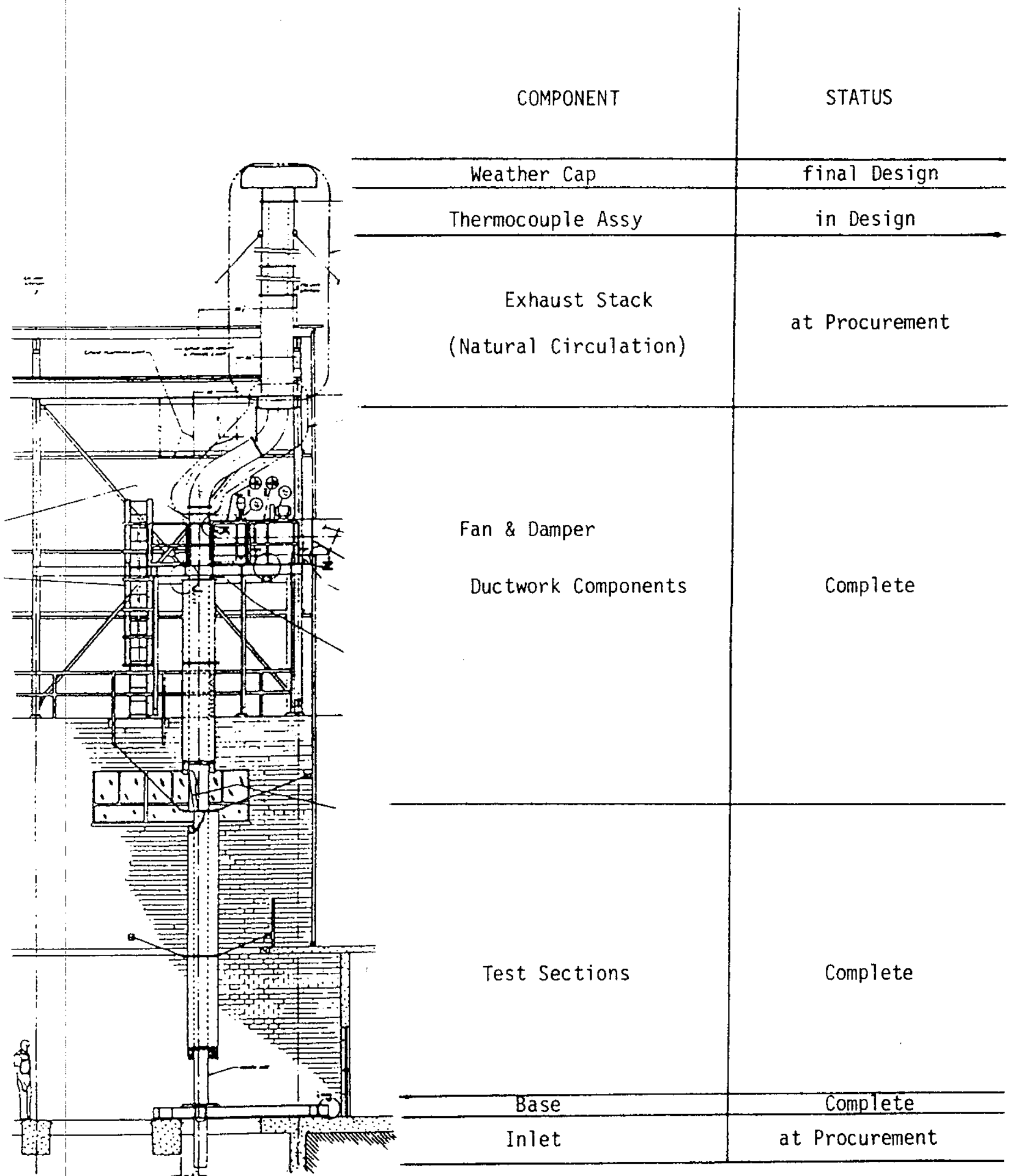

e.c.0\%

Figure 3. Mechanical Design and Fabrication Status 


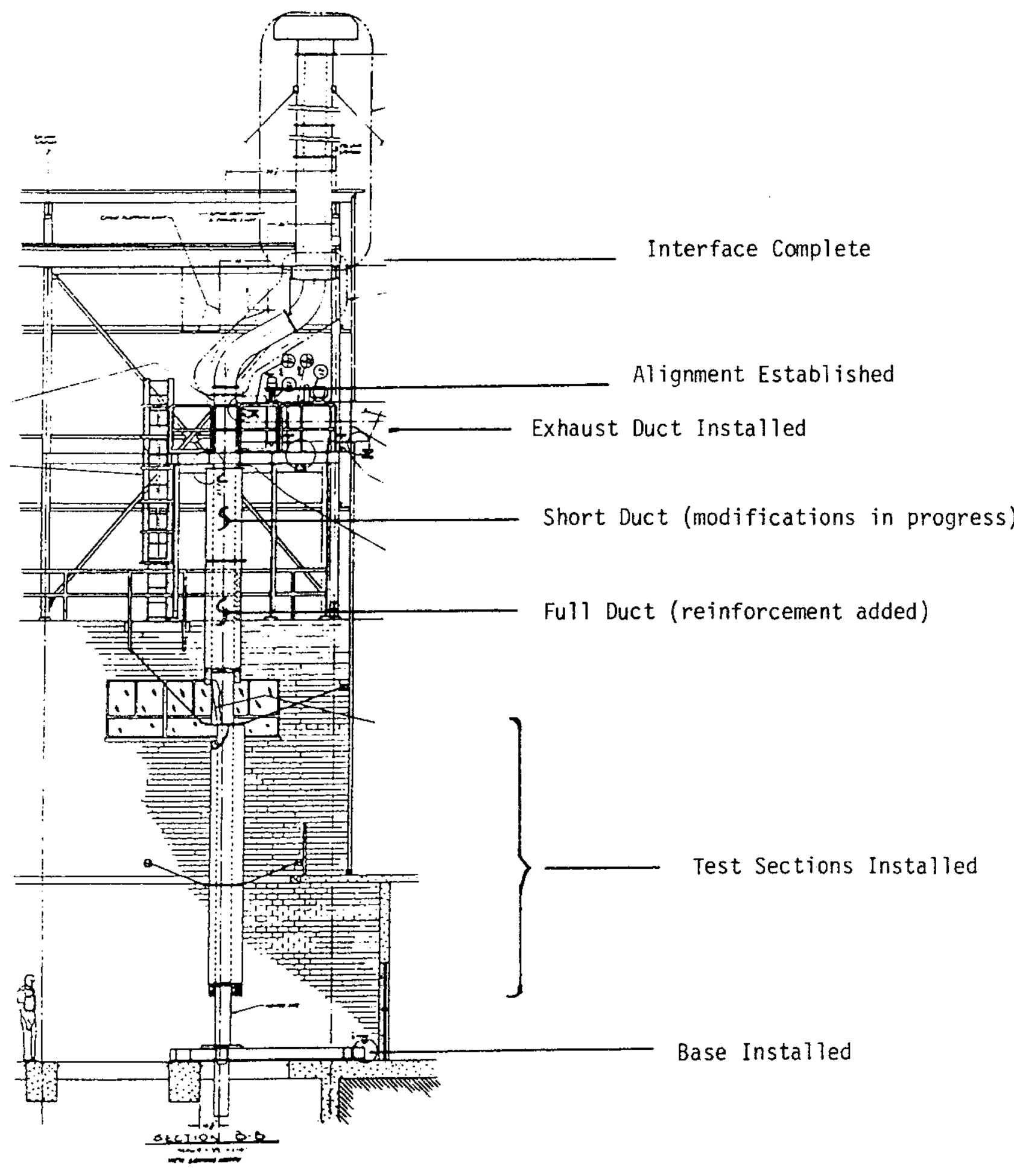

Figure 4. Mechanical Assembly Status 
- Service platform installed.

- Forced circulation fan and damper procured.

- Support base fabricated and installed.

- 2-part test section fabricated and installed, thermocouples attached.

- Ductwork between test section and exhaust stack fabricated.

Mechanical activities in progress include:

- Final mechanical assembly drawings.

- Pitot/temperature traverse mechanism support development.

- Procurement of exhaust fan, stack ductwork, weather cap, weather tower.

- Exhaust stack thermocouple assembly design and fabrication.

Figure 5 shows the two $11 \mathrm{ft}$. vertical test section modules in place with the attached thermocouple leads. Figure 6 is a view of the upper $11 \mathrm{ft}$. section, showing the side plates and insulation (between side plates and the , heated plate) from the heated plate (back side).

\subsection{Electrical Systems}

\subsubsection{Heater System}

The heater system design as shown in figure 7 is not different from that shown in reference 1. Heater resistances have been measured to provide input data for on-line calculation of "local" power (heat flux) during experiments ( $E^{2} / R \times S C R$ on-time). Figure 8 shows a typical heater "zone" ready for assembly to the test section. There are 5 heater 


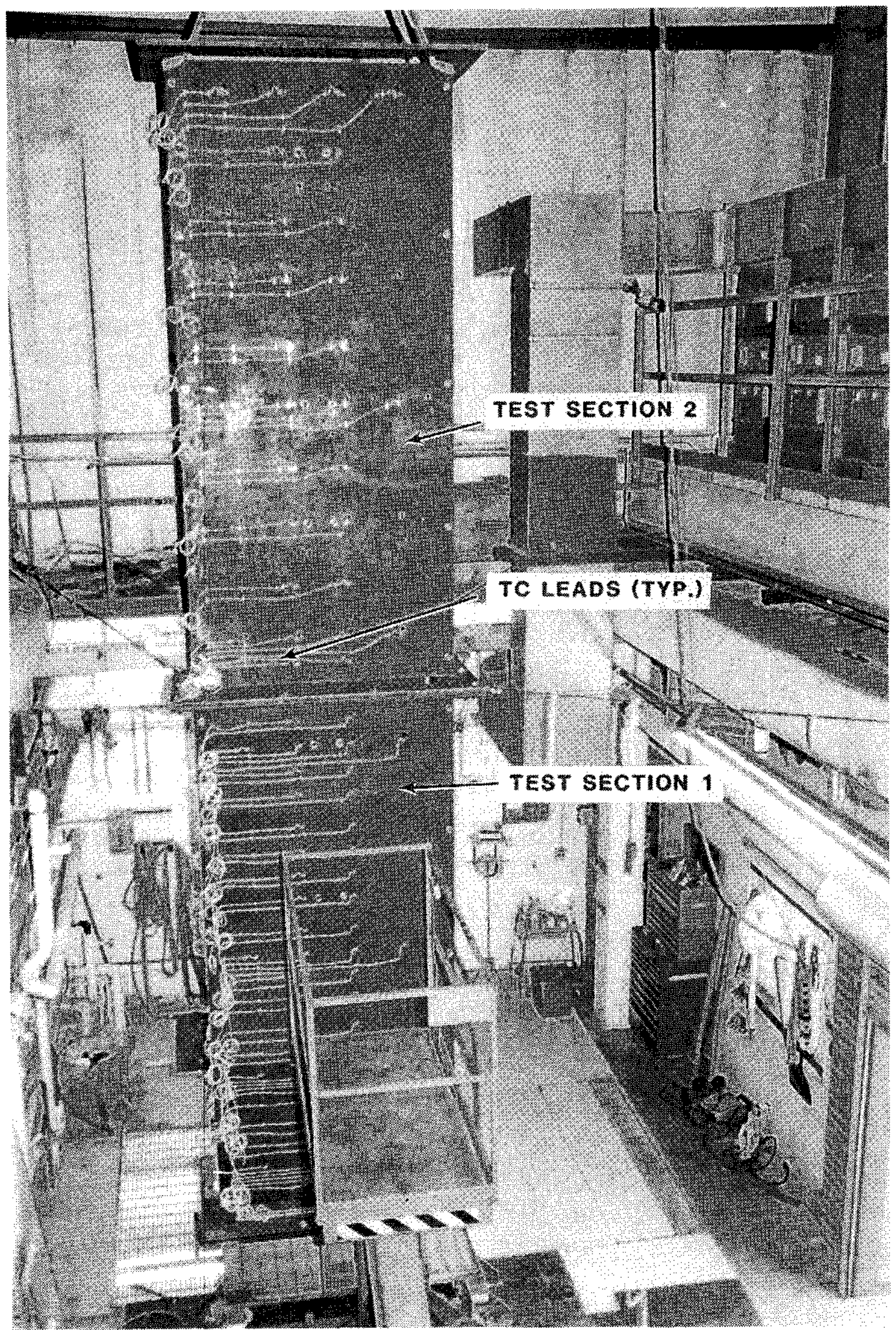

Figure 5. Test Section in Place 
$-8-$

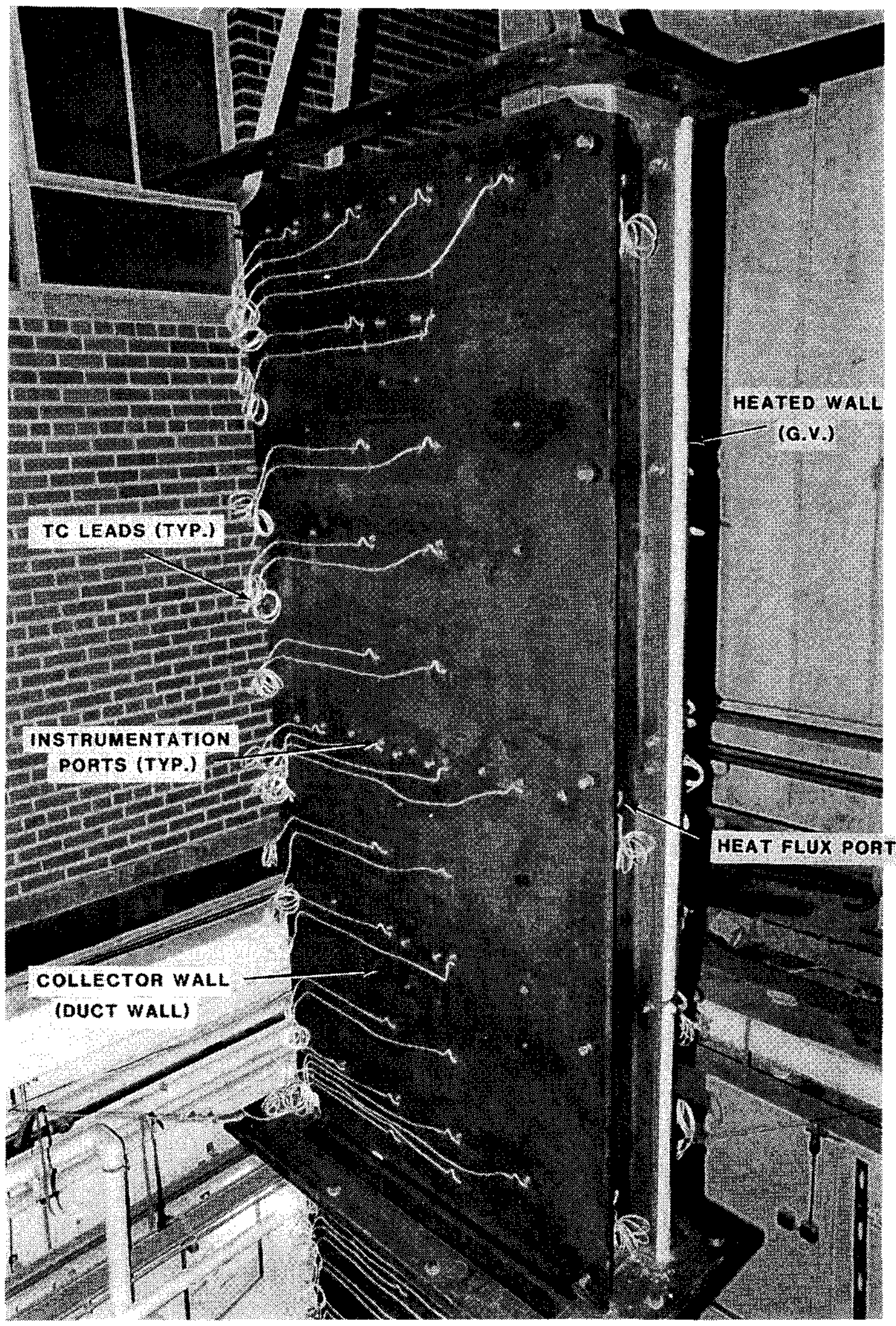

Figure 6. Upper Test Section in Place 


\section{HEAIER CONIROL}

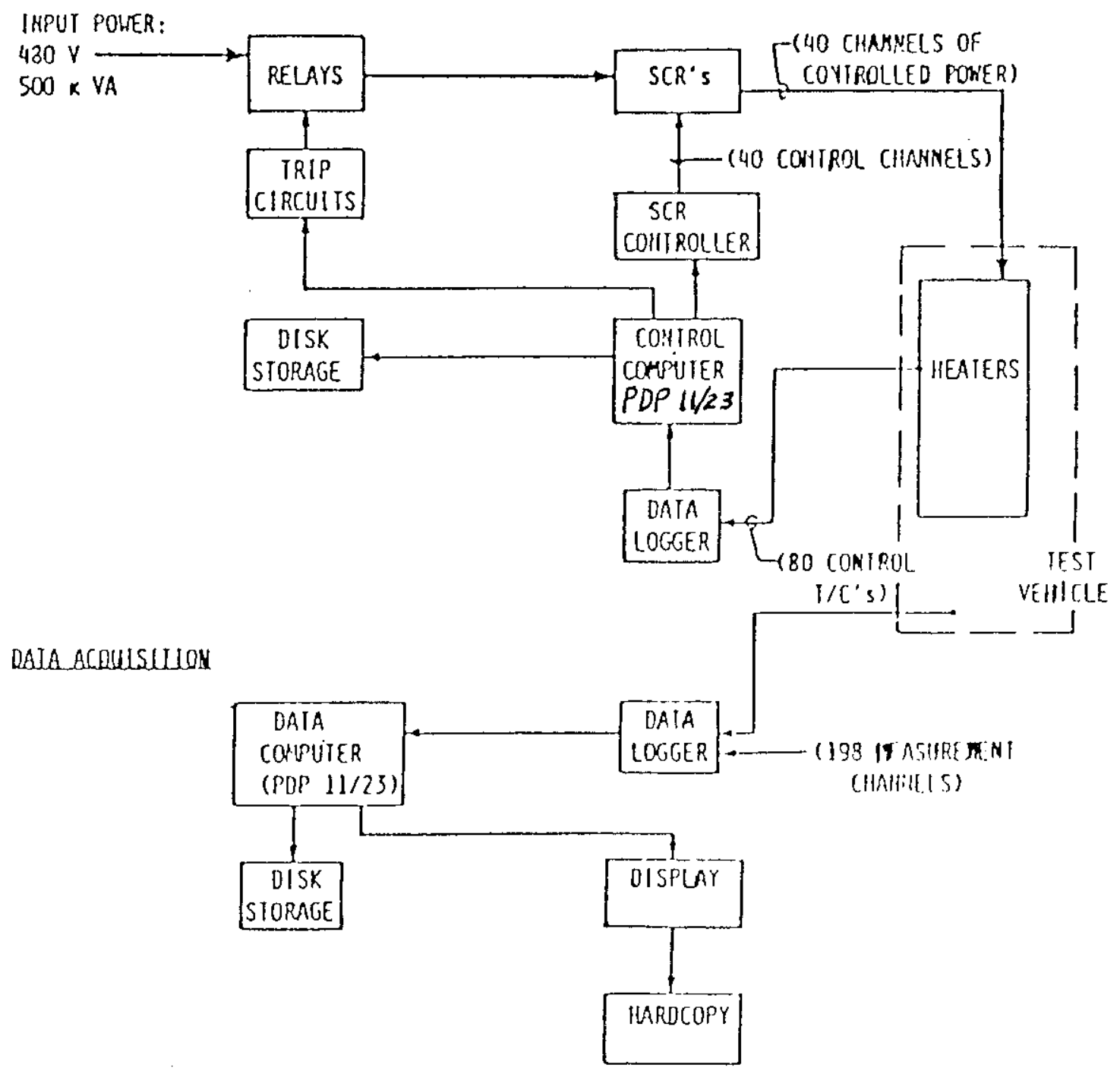

Figure 7. RVACS Heater Control and DAS System 
$-10-$

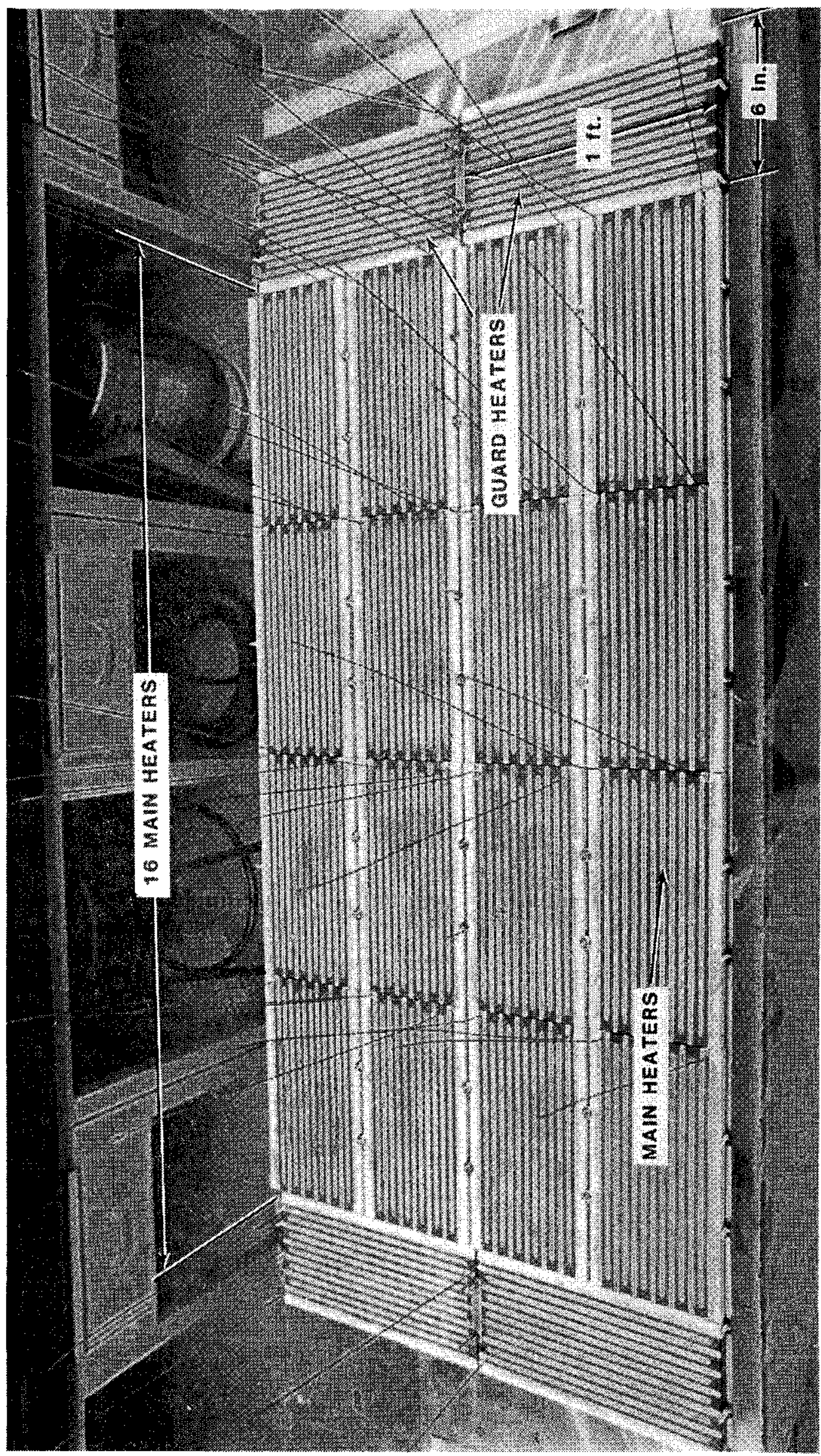

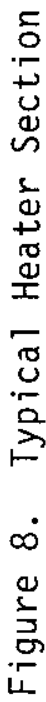


plate zones per 11 foot test section, each with individual heater control (including guard heaters). The center 16 heaters on the heater plate represent one heater zone with the four edge heaters being guard heaters. This array of 20 plate heaters represents $10 \%$ of the total heated length in the 22 foot test arrangement. Figure 9 is a closeup picture showing details of the heater leads and the control thermocouple locating studs.

These heaters are designed to operate at $120 \mathrm{~V}$ each in strings of four (in Figure 8, the heaters will be wired in series-parallel for $480 \mathrm{~V}$ operation). The design limit of the heaters is $2200^{\circ} \mathrm{F}$ and $1 / 2 \mathrm{~kW}$. This is substantially more power than required for testing; the heater temperature will be controlled and 1 imited to $1600^{\circ} \mathrm{F}$ operation. The $440 \mathrm{~V}$ power supply and buses are in the installation phase.

\subsubsection{Auxiliary and Instrument Power}

In addition to heater power, several system components require $110 \mathrm{~V}$ service:

- Service power (1ighting, etc.).

- Variable speed, reversible fan and damper control power.

- Control console and instrument power (Figures 10 and 11).

- On-line computers/DAS systems (Figures 10 and 11).

The service power and fan/damper power are in the installation phase.

Assembly of the control console is essentialiy complete, as shown in Table I. Final system checkout will occur when all sensor/transducer connections are complete. 


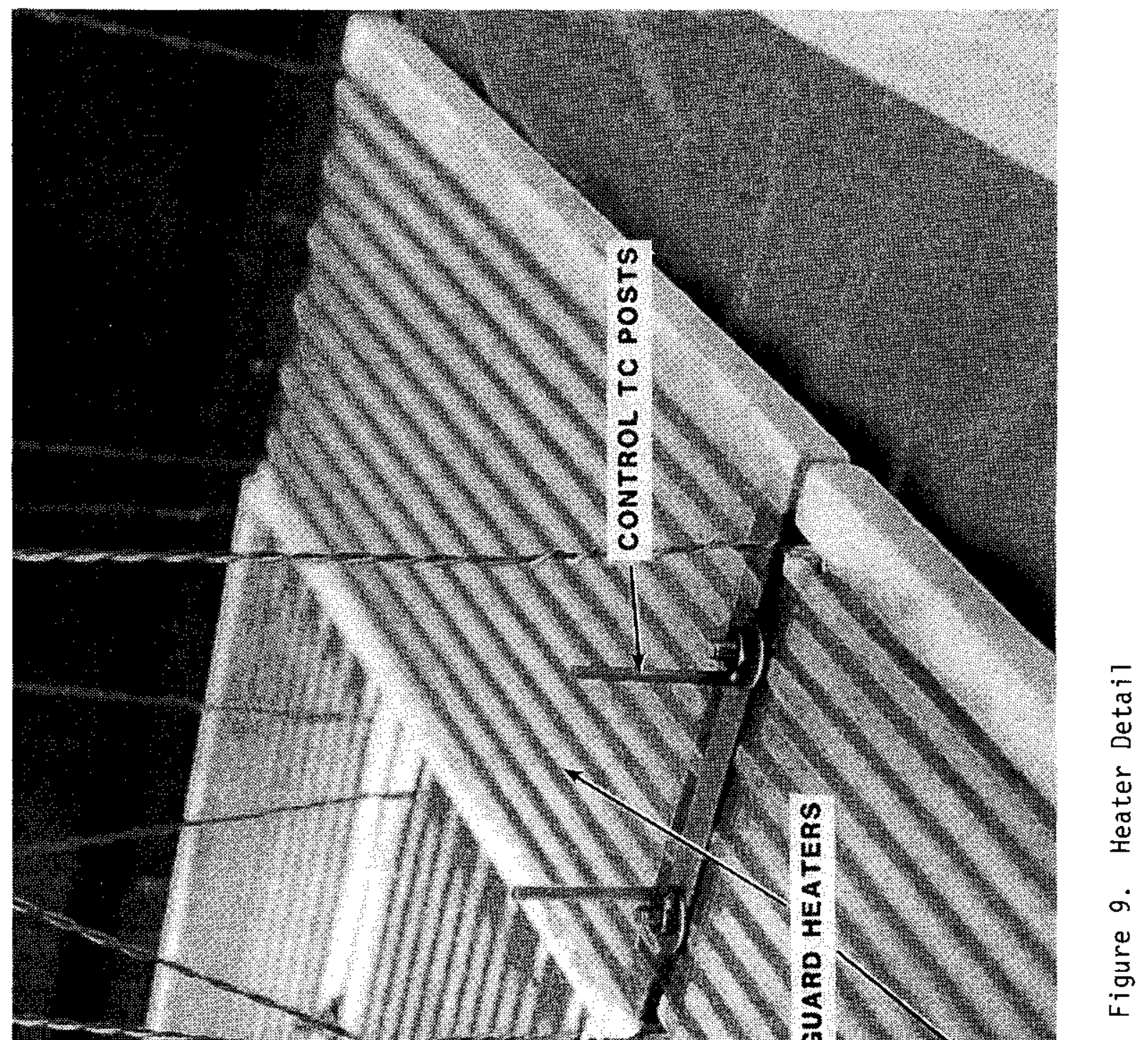




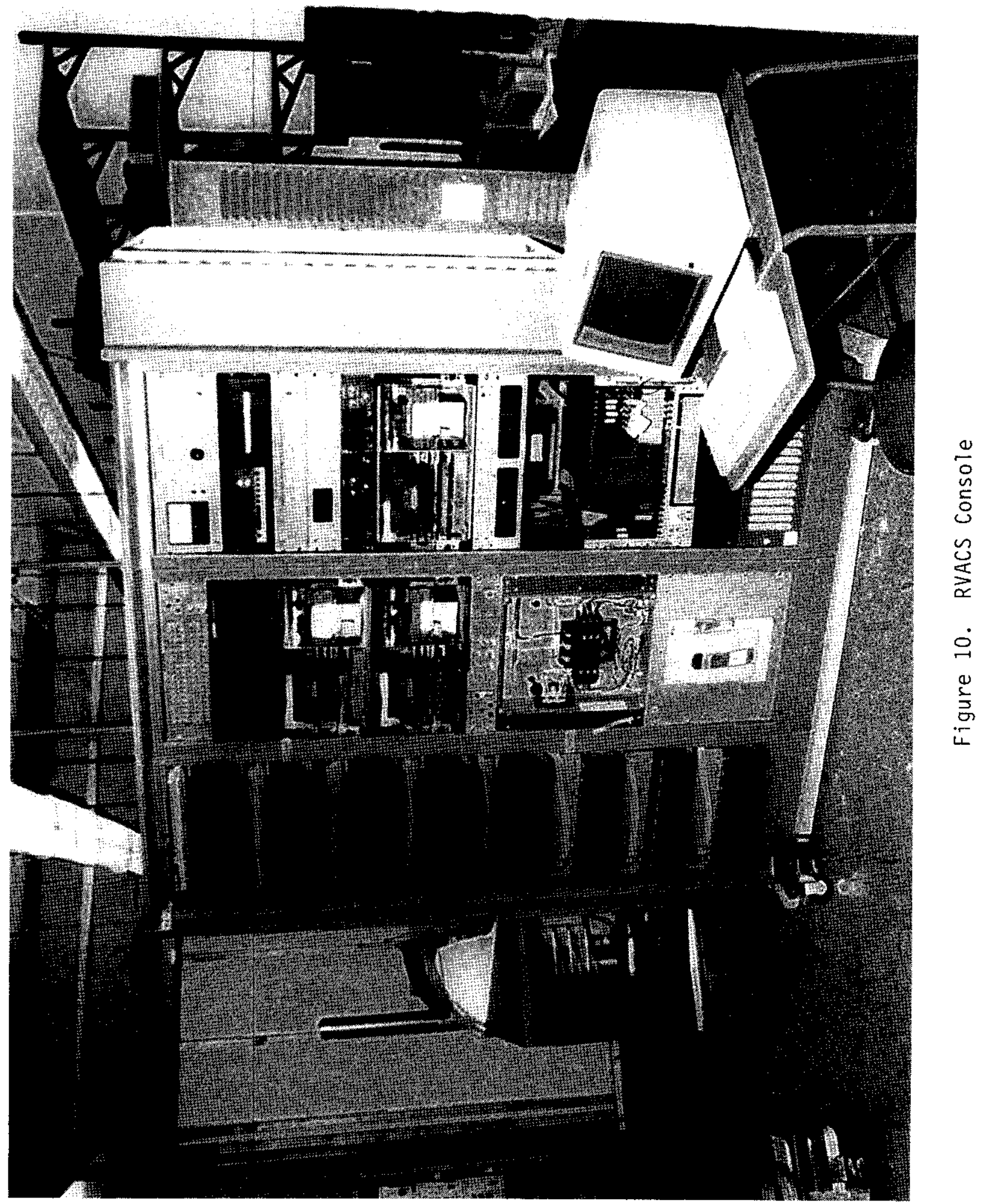




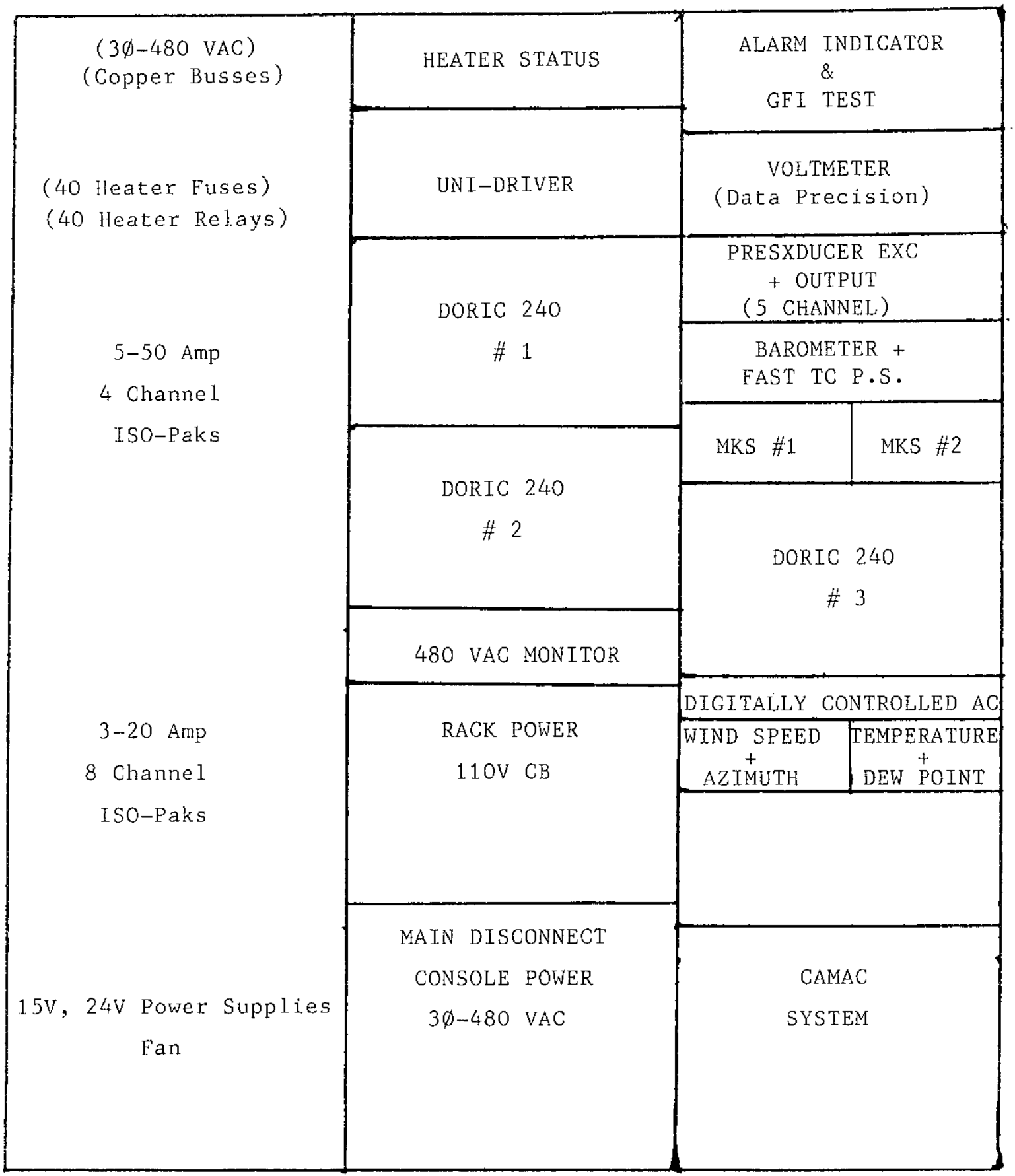

Figure 11. RVACS Console Configuration 
Table I. Control Console Status

\section{RVACS Control Console}

Custom/Semicustom Subsystem

$\underline{\text { Status }}$

Alarm Indicator Chassis

Complete

Ground Fault Interrupt GFI

Complete*

Heater Status and Contractor Drive

Complete

480 VAC 30 main \& Console Monitors

Complete

5-Channe 1 Pressure Monitor

Complete

8-Channe1 Digitally Controlled 110 VAC

Complete

Barometer \& Fast TC Inputs

Complete

Access Panel (TC's \& Voltage Inputs)

Complete

Traversing Mechanism Driver Interface

Complete

Commercial Subsystems

2 Mks (Baratron) Units Measurement System \& Interface Complete Unidriver/CAMAC Interface

Complete

3-100 Channe 1 DORIC 240

Complete

Wind and Azimuth System

Complete*

Temperature \& Dew Point Unit

Complete*

\section{Console Power System}

$3 \emptyset 480$ VAC Power Circuit (Left Bay) Complete

- Main $3 \emptyset$ Copper Buses

Comp lete

- Heater Fuse Blocks

Complete

- Heater Relays (contractors)

Complete

- Iso-Paks/Unidriver

Complete

$3 \emptyset 110$ VAC Console Instruments/Control Power

Complete

- $15 \mathrm{~kW} 3 \emptyset$ 480V/120V Transformer

Complete

- 3ø Fused Disconnect Switch

Comp lete

- 6-20A Load Circuit Breakers

Complete

* Not completely checked out. 


\subsection{Instrumentation}

The instrumentation requirements (Table II) have been revised to reflect some changes in secondary experiment objectives and test planning. The status of instrumentation is as follows:

- All of the thermocouples for the heated wall and the duct wall have been installed.

- The 10 radiation shielded TC assemblies, pitot tubes, and the radiation sensors are in procurement.

- The outlet air flow sensor, the stationary pressure sensors, and the heater $A C$ instruments are ready for installation and/or connection to the DAS/control systems.

- A meteorological tower will be installed on the building to measure wind direction, velocity and temperature.

\subsection{Data Acquisition System (DAS)}

The DAS/heater control system block diagram is shown in Figure 12. A considerable amount of detailed software effort has been completed (naming variables, etc.). The following description is an overview of the DAS/heater control status.

\subsubsection{DAS Operations}

At periodic intervals the following parameters are recorded:

- All sensors connected to the Doric data loggers.

- Unidriver settings.

- Power input to each heater. 
Table II. Instrumentation Requirements - RVACS

\begin{tabular}{|c|c|c|c|c|c|}
\hline \multirow{2}{*}{$\begin{array}{l}\text { INSTRUMENTATION } \\
\text { DESCRIPTION }\end{array}$} & \multicolumn{5}{|c|}{ MINTMUM REQUTRED VALUES } \\
\hline & QUANTITY' & RANGE & ACCURACY ${ }^{2}$ & & RESPONSE 3 \\
\hline \multicolumn{6}{|l|}{ THERMOCOUPLES } \\
\hline Heater Overtemperature & 2 per heater circuit & 0 to $1900^{\circ} \mathrm{F}$ & $\pm 4^{\circ} \mathrm{F}$ or $\pm 0.75 \%$ & & $30 \mathrm{sec}$ \\
\hline Guard Vessel & $\begin{array}{c}2 \text { per heater circuit } \\
\text { and } \\
2 \text { per } 2 \mathrm{ft} \text { elevation } \\
\text { of test section }\end{array}$ & 0 to $1300^{\circ} \mathrm{F}$ & $\pm 4^{\circ} \mathrm{F}$ or $\pm 0.75 \%$ & & $30 \mathrm{sec}$ \\
\hline Duct Wall & $\begin{array}{l}2 \text { per } 2 \mathrm{ft} \text { elevation } \\
\text { of test section }\end{array}$ & 0 to $900^{\circ} \mathrm{F}$ & $\pm 4^{\circ} \mathrm{F}$ or $\pm 0.75 \%$ & & $30 \mathrm{sec}$ \\
\hline Side Wall & $\begin{array}{l}2 \text { per } 4 \mathrm{ft} \text { elevation } \\
\text { of test section }\end{array}$ & 0 to $900^{\circ} \mathrm{F}$ & $\pm 4^{\circ} \mathrm{F}$ or $\pm 0.75 \%$ & & $30 \mathrm{sec}$ \\
\hline Fins & $\begin{array}{l}2 \text { per } 2 \mathrm{ft} \text { elevation } \\
\text { of test section }\end{array}$ & 0 to $900^{\circ} \mathrm{F}$ & $\pm 4^{\circ} \mathrm{F}$ or $\pm 0.75 \%$ & & $30 \mathrm{sec}$ \\
\hline Inlet Air & 2 & 0 to $300^{\circ} \mathrm{F}$ & $\pm 4^{\circ} \mathrm{F}$ or $\pm 0.75 \%$ & 30 & $\sec \theta 2$ FPS \\
\hline Outlet Air & 2 & 0 to $500^{\circ} \mathrm{F}$ & $\pm 4^{\circ} \mathrm{F}$ or $\pm 0.75 \%$ & 30 & sec 2 FPS \\
\hline \multicolumn{6}{|l|}{ VELOCITY SENSOR } \\
\hline $\begin{array}{l}\text { Outlet Air } \\
\text { (for flow rate measurement) }\end{array}$ & 1 & $2-30$ FPS & $\pm 5 \% \mathrm{FR}$ & & $30 \mathrm{sec}$ \\
\hline \multicolumn{6}{|l|}{ PRESSURE SENSORS } \\
\hline Inlet Static (absolute) & 1 & $\begin{array}{l}\text { Barometric } \\
(600-825 \mathrm{~mm} \mathrm{Hg})\end{array}$ & $1 \mathrm{~mm} \mathrm{Hg}$ & & $1 \mathrm{sec}$ \\
\hline Test Section Differentials & 3 & $0-1 \mathrm{~min} \mathrm{Hg}$ & $\pm 0.3 \% \mathrm{FR}$ & & $1 \mathrm{sec}$ \\
\hline \multicolumn{6}{|l|}{ HEATER AC SUPPLY MEASUREMENTS } \\
\hline Voltage & 3 & $0-500 \mathrm{~V}$ & $\pm 0.5 \% \mathrm{FR}$ & & $30 \mathrm{sec}$ \\
\hline Power & 1 & $0-500 \mathrm{~kW}$ & $\pm 2 \% \mathrm{FR}$ & & $30 \mathrm{sec}$ \\
\hline HUMIOITY MEASUREMENT & 1 & $\begin{array}{l}0-98 \% \mathrm{RH} \\
0-212^{\circ} \mathrm{F}\end{array}$ & $\begin{array}{l} \pm 3 \% \text { RH } \\
\pm 4^{\circ} \mathrm{F} \text { or } \pm 0.75 \%\end{array}$ & & $\sec \theta 2$ FPS \\
\hline $\begin{array}{l}\text { RADIATION SEHSOR } \\
\text { (for heat flux measurement) }\end{array}$ & 4 & $0-1.0 \mathrm{BTHJ} / \mathrm{ft}^{2}+\mathrm{sec}$ & $\pm 3 \% \mathrm{FR}$ & & $1 \sec$ \\
\hline MOVNBLE SENSORS ${ }^{4}$ & 3 each & & & & \\
\hline Pitot Tube & duct wall access ports & $2-30$ FPS & & & \\
\hline $\begin{array}{c}\text { Differential Pressure } \\
\text { and Temperature } \\
\text { with radiation shield }\end{array}$ & $\begin{array}{l}4 \text { located at } \\
4 \text { per } 4 \text { ft elevation } \\
\text { of test section }\end{array}$ & $\begin{array}{c}0-1 \mathrm{~mm} \\
0-500\end{array}$ & $\begin{array}{c} \pm 0.3 \% \mathrm{FR} \\
\pm 4^{\circ} \mathrm{F} \text { or } \pm 0.75 \%\end{array}$ & 30 & $\sec a 2$ FPS \\
\hline Hot Wire Anemometer & $\begin{array}{c}\text { duct wall access ports } \\
\text { located at } \\
4 \text { per } 4 \mathrm{ft} \text { elevation } \\
\text { of test section }\end{array}$ & $0-30$ FPS & $\pm 1 \% \mathrm{FR}$ & & isec \\
\hline $\begin{array}{l}\text { Radiation Sensor } \\
\text { (for emissivity measurement) }\end{array}$ & $\begin{array}{c}\text { side wall access ports } \\
\text { located at } \\
1 \text { per } 4 \mathrm{ft} \text { elevation } \\
\text { of test section }\end{array}$ & $0.1 .0 \mathrm{BTH} / \mathrm{ft}^{2}-\mathrm{sec}$ & $\pm 3 \% \mathrm{FR}$ & & $1 \mathrm{sec}$ \\
\hline
\end{tabular}

NOTES:

1. Additional quantities of each 1 tem may be 1ncorporated with the maxtmum sampling limfted by the data recording system. The data recording system must be capable of accepting up to 297 signals and must be capable of sampling the complete set of signals at a periodic rate not to exceed one minute.

2. The accuracy inciudes linearity and repeatability. If two values are presented, the greater value indicates the accuracy.

3. The response is the time required to equal $63 \%$ of instantianeous change.

4. A separate data recording system (in addition to that identified in Note 1) must be capable of recording the signals from the movable sensors. 


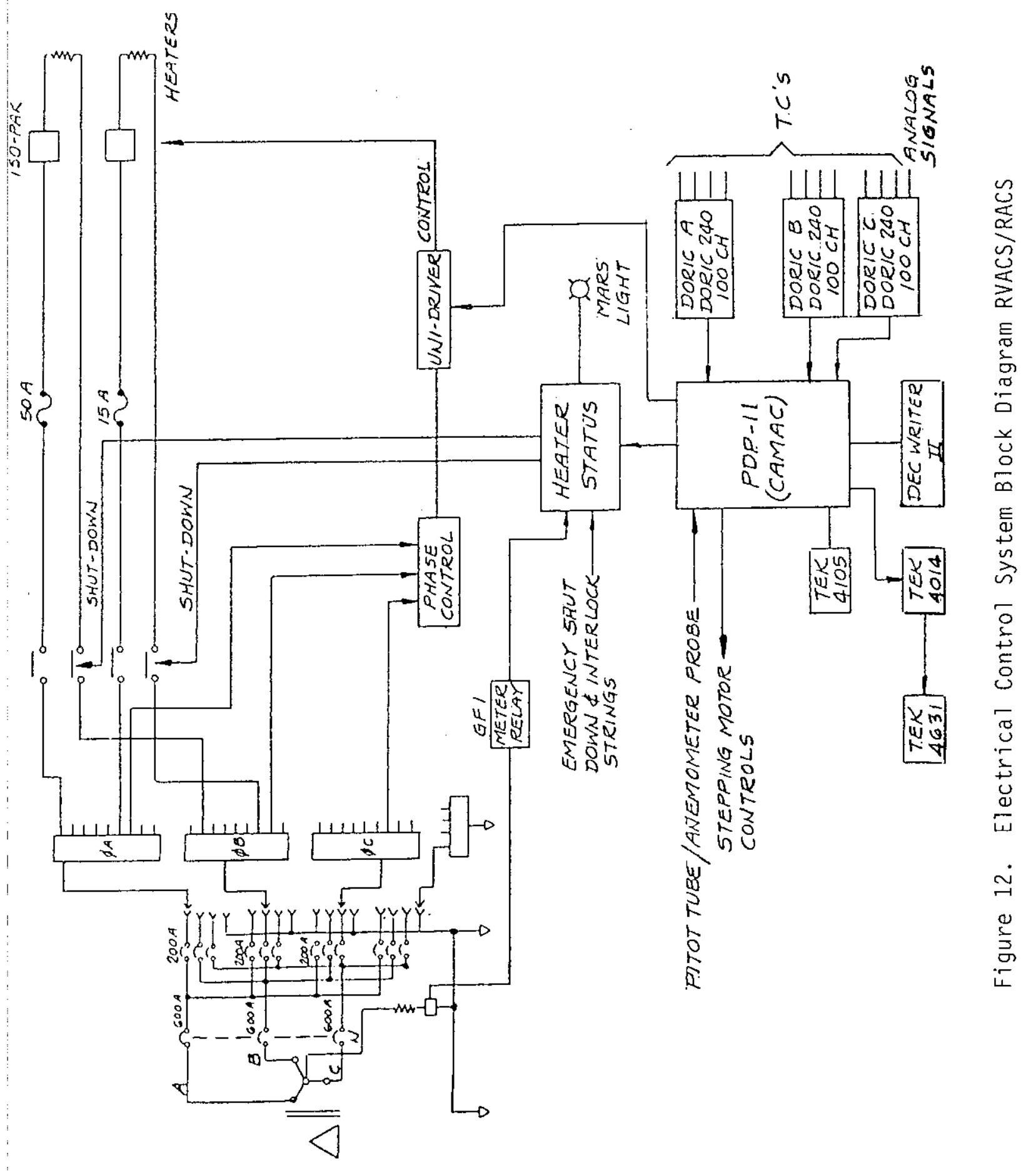


- Control temperature for each heater.

- A moderate number of calcuiated parameters (TBD).

The heater control algorithm treats each heater string as a separate entity. The heaters are numbered from 1 to 20 . Heater 1 is the edge heater for the lowest two foot section, heater 2 the main heater for the first two foot section, etc. Each heater has the following associated variables:

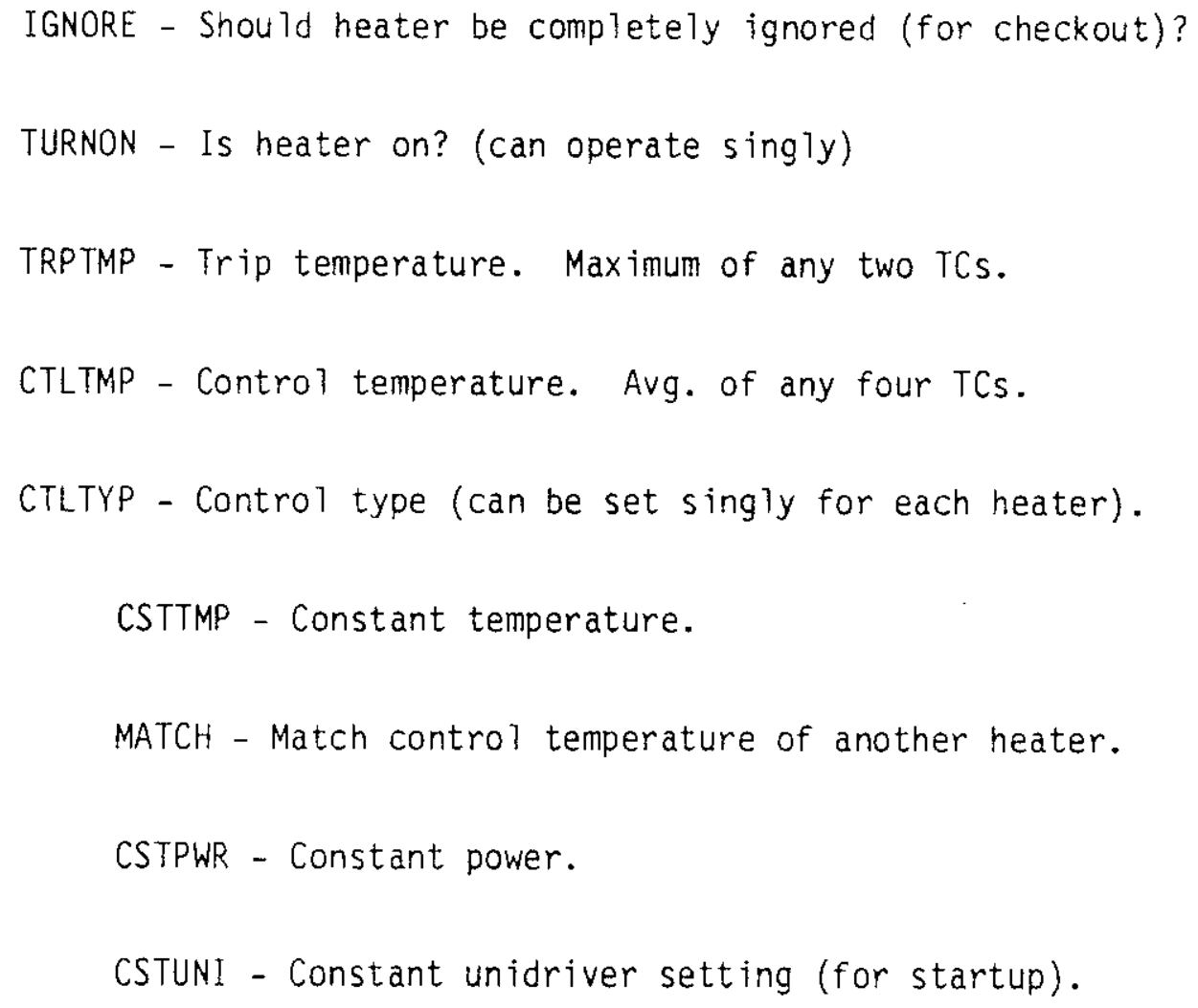

\subsubsection{DAS Sof tware - Completed Activities}

The data processing and display programs (from previous experiments) have been modified to al low for the larger number of parameters required by RVACS. 
Camac Checkout Program

CAU - CAMAC Utility. General purpose, but tedious, CAMAC checkout.

TAI - Test Analog Input.

TDI - Test Digital Input.

TDO - Test Digital Output. Includes special command for Unidriver.

MKS - Test MKS Pressure Transducers.

SMC - Test Stepping Motor Controller.

Note: These programs have been used to check a11 CAMAC interfacing.

Data Acquisition

DAQTSK - Actual data acquisition task. This program, except for conversion algorithms, is written - has been partially tested.

DAQ - Operator interface for DAQTSK.

\section{Heater Control}

DAQTSK - Also performs heater control. Written but not tested.

HTR - Operator interface for heater control.

$\mathrm{HCL}$ - Heater control listing.

HCP - Heater control plotting.

\subsubsection{DAS Software - Remaining Activities}

- DAQTSK - Conversions for a 11 non-TC parameters -- heater power, $A C$ voltage, differential pressure, meteorological data.

- Probe (traverse mechanism) data acquisition and control.

- Special data reduction and displays.

- Lists/diagrams showing signal and power routing. 


\subsection{Test Plan}

From the available design descriptions for the PRISM concept, it appears that the Air-Side Fu11-Scale Tests performed at ANL should encompass a range of heat fluxes, flow resistances and weather conditions that could exist following an inherent reactor shutdown wherein decay heat removal is entirely dependent upon the passive free convection effects of air flow between the reactor guard vessel (G.V.) and the surrounding duct wall. The initial (Phase I) test plan for the no-fin case is predicated on the following general conditions and strategy:

A. Thermal

1. Uniform G.V. wall temperature distribution to a maximum of $900^{\circ} \mathrm{F}\left(482^{\circ} \mathrm{C}\right)$.

2. Uniform G.V. heat flux to $2 \mathrm{~kW} / \mathrm{ft}^{2}\left(\sim 20 \mathrm{~kW} / \mathrm{m}^{2}\right)$.

3. Stepwise variable heat flux in the axial direction to simulate possible stratification of sodium temperatures in the reactor vesse?.

4. Prototypic wall emissivities.

B. Fluid Dynamics

1. Very low flow resistance (initial test assembly loss coefficient, $k \cong 1.5$ ) to a loss coefficient of approximately ten $(K=10)$, referenced to the heated section cross-sectional area.

2. Flow channel dimensions will simulate a portion of the G.V. and duct wall design such that the air velocity profiles are prototypic. 
C. It has been speculated that weather (particularly wind) conditions may affect the RVACS performance. Initially, the tests will be performed with the weather cap in place. outside and inside ambient conditions will be monitored during testing and possible effects will be investigated. Selected test runs will be duplicated with the weather cap removed or replaced with low loss weather cap.

D. The test matrix as proposed at the ANL/GE meeting of 2/19/86 contains a large number of possible parametric sets for data collection. In addition, the possible number and location of air flow measurements (pressure and temperature) is large. This initial (Phase I) plan proposes to collect data at selected matrix points in relatively large parameter increments and a smali number of pitot tube and thermocouple traverses to minimize experiment durations and data acquisition storage requirements. The results of Phase I operation will determine the required extent of the test matrix for Phase II.

E. The Phase I test matrix and possible Phase II (extended) test descriptions are presented in Table III. 


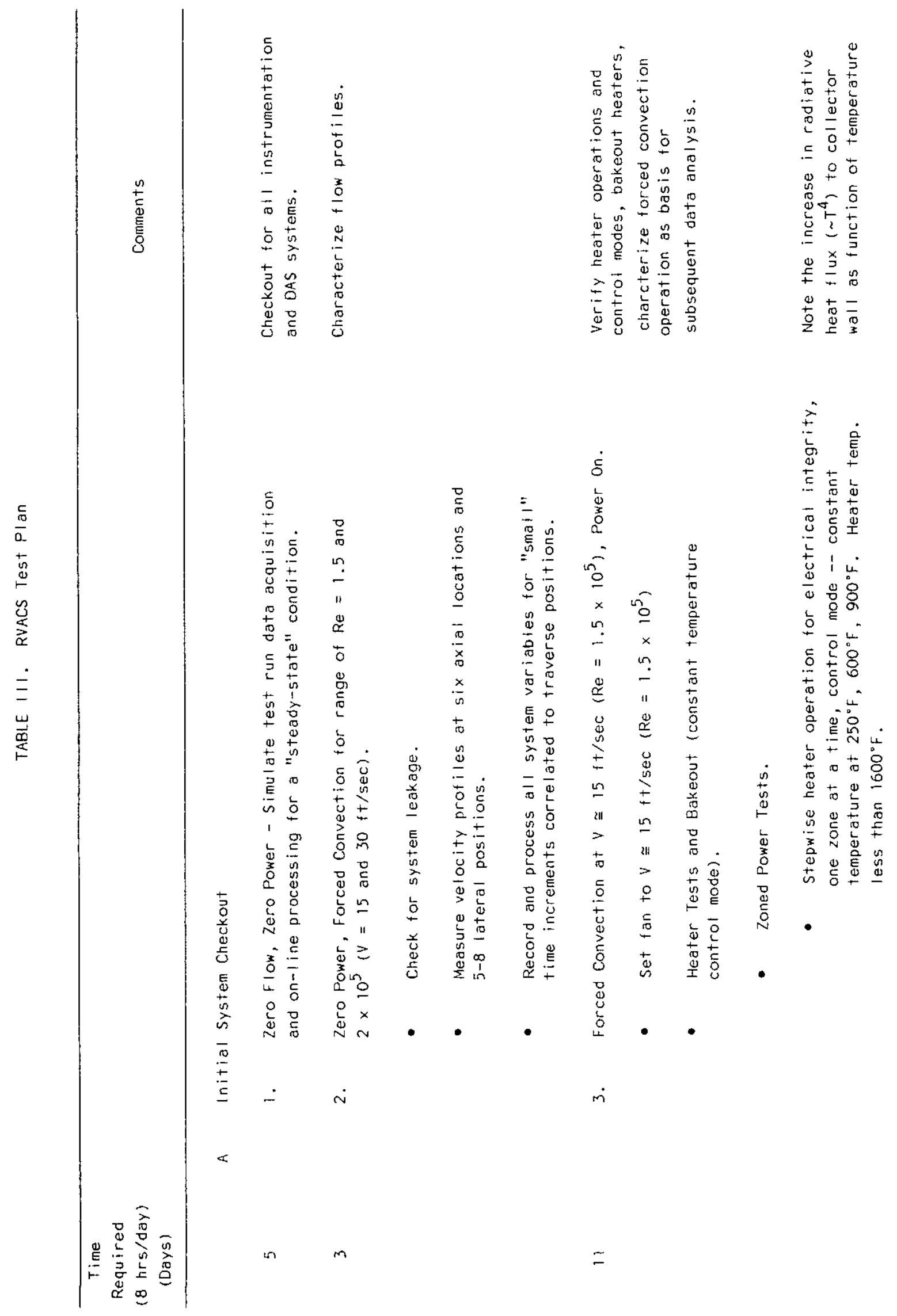




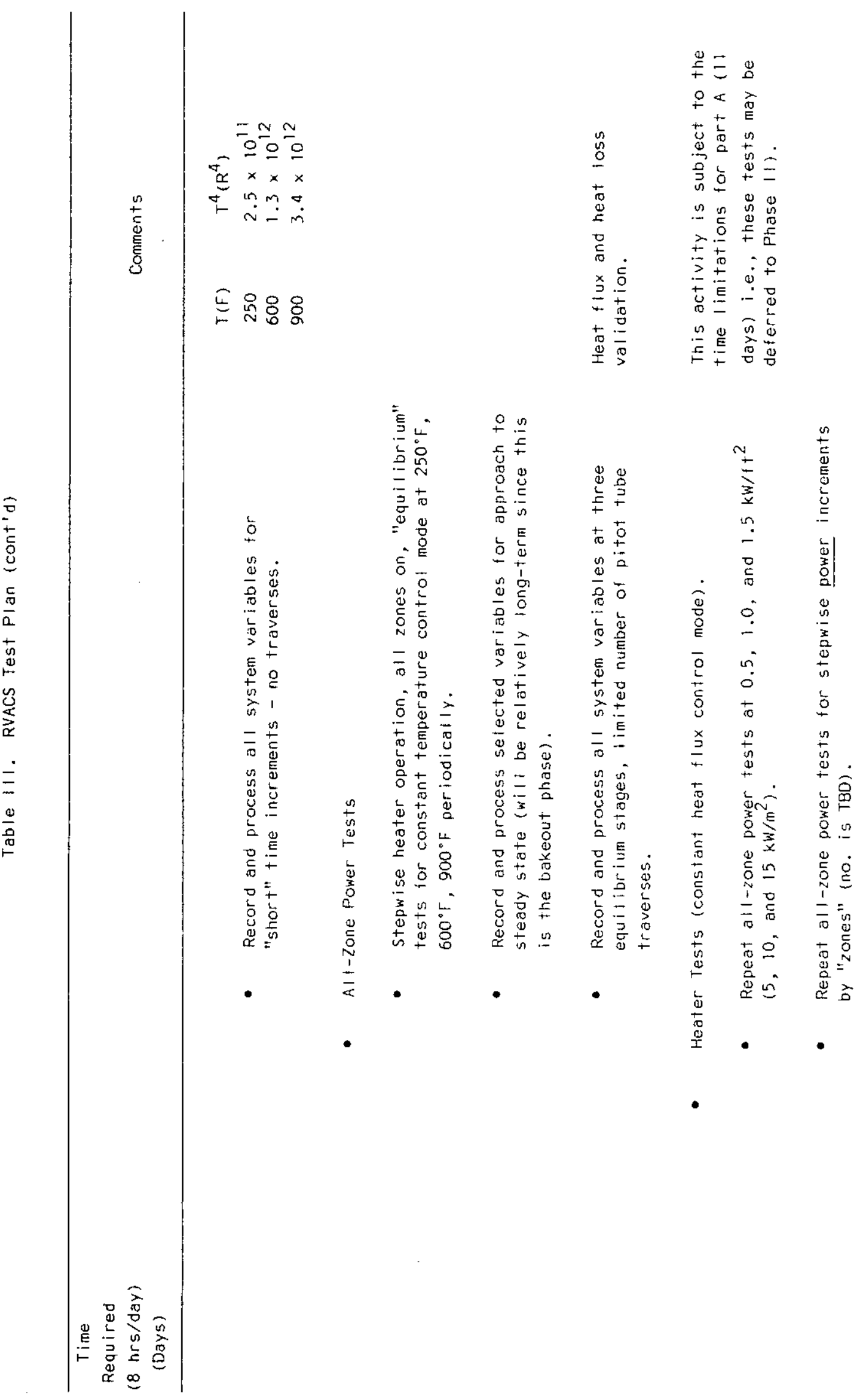




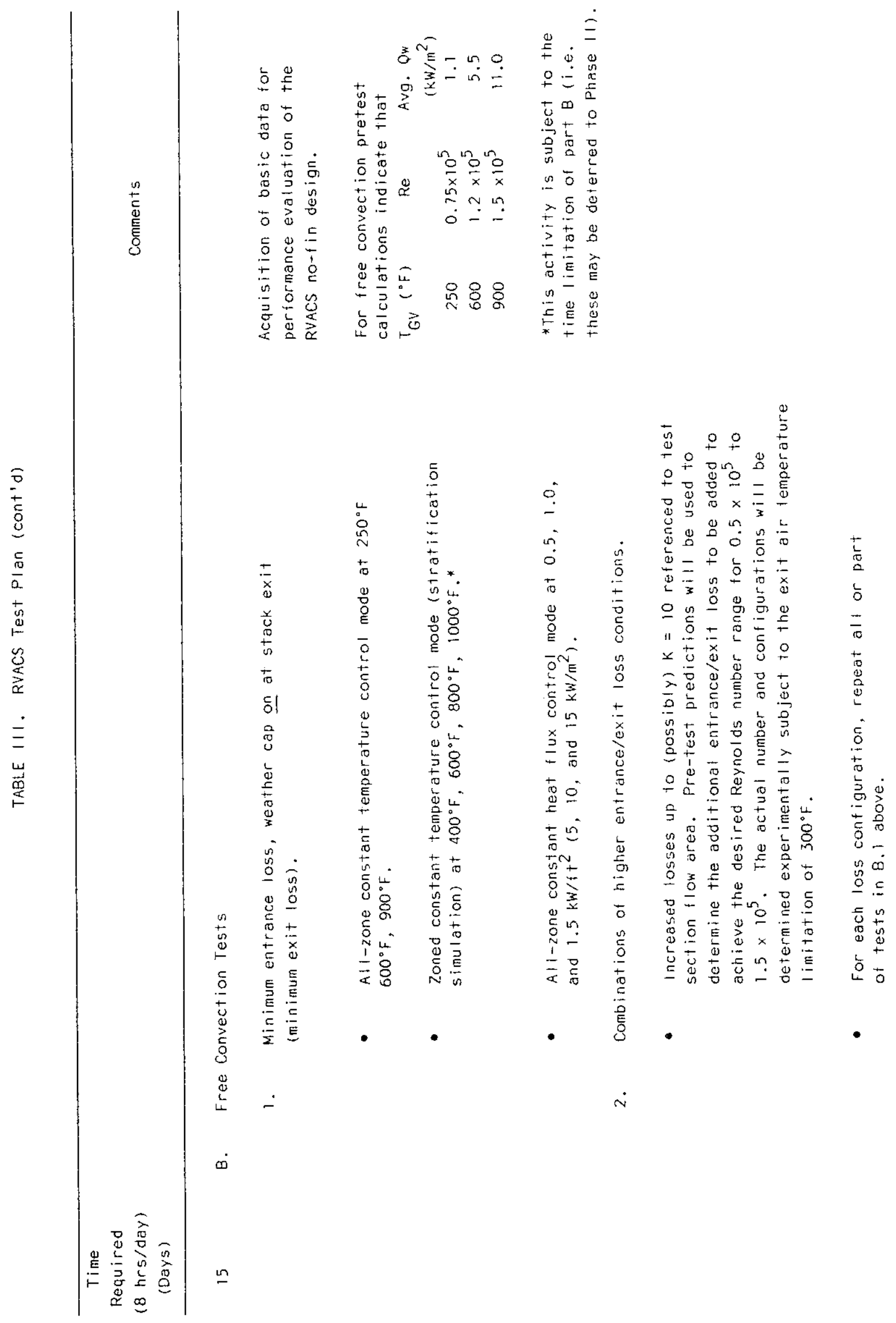




\subsection{PRE-TEST ANALYSIS}

\subsection{Lumped Parameter Analysis}

A variety of pre-test analyses of the RVACS test assembly have been performed to support the design and predict system performance for various operating conditions. The thermal model used is the same as that presented in Ref. [11. However, the air flow model has been changed to use form losses instead of the previous factor " $\Omega$ ": $(\Omega=$ pressure loss in heated zone/total system pressure loss). The model has also been upgraded to remove the previous assumption of air density being a linear function of temperature.

\subsubsection{Model Development}

The revised air flow equations are:

\section{Net thermal head}

$$
\Delta P_{h}=\rho_{0} g\left[\left(1-\bar{\rho} / \rho_{0}\right) L_{h}+\left(1-\rho_{s} / \rho_{0}\right) L_{S}\right]
$$

where

$$
\begin{aligned}
& \Delta P_{h}=\text { thermal head } \\
& \rho_{0}=\text { air density at inlet } \\
& \vec{\rho}=\text { average air density in the heated zone } \\
& \rho_{S}=\text { air density above heated zone } \\
& L_{h}=\text { heated length } \\
& L_{S}=\text { stack length } \\
& g=\text { acceleration due to gravity }
\end{aligned}
$$

To calculate the average air density, $\bar{p}$, two assumptions are employed: 
1. the air temperature rises linearly in the heated zone, * (constant heat flux case)

2. the pressure change is small relative to atmospheric pressure

from assumption no. 1, we have:

$T_{L}=T_{0}+\frac{T_{a}-T_{0}}{L_{h}} L$

where:

$L=$ distance from inlet

$T_{L}=$ air temperature at location $\mathrm{L}$

$T_{\mathrm{a}}=$ air temperature at exit of heated zone

from assumption no. 2, we have, using the ideal gas law:

$$
P V=R T_{L}
$$

or: $\rho T_{L}=P / R=$ constant

so that: $\rho=\frac{\rho_{0} T_{0}}{T_{L}}=\frac{\rho_{0} T_{0}}{T_{0}+\left(T_{a}-T_{0}\right)\left(\frac{L}{L_{h}}\right)}$

then:

$$
\begin{aligned}
& \bar{\rho}=\frac{1}{L_{h}} \int_{0}^{L_{h}} \rho d L \\
& \bar{\rho}=\rho_{0}\left[\frac{\ln \left(T_{a} / T_{0}\right)}{T_{a} / T_{0}-1}\right] .
\end{aligned}
$$

* Note:

An analysis was made to determine the error incurred when this assumption is retained for the case of the guard vessel wall temperature held constant. This demonstrated that an error in velocity of only $1.3 \%$ or less results for velocities of 5 fps or greater. 


\section{Pressure Losses}

\section{A. Friction Loss in Heated Zone}

Again invoking the two assumptions given above, the frictional pressure loss, $\Delta \mathrm{P}_{\mathrm{fh}}$, in the heated zone can be evaluated from:

$$
\int_{0}^{L} h d P_{f h}=\frac{2 f_{h} G_{h}^{2}}{D_{h} \rho_{0} T_{0}} \int_{0}^{L_{h}}\left[T_{0}+\left(\frac{T_{a}-T_{0}}{L_{h}}\right) L\right] d L
$$

or

$$
\Delta P_{f h}=\frac{f_{h} G_{h}^{2}}{D_{h} \rho_{0}}\left[L_{h}\left(1+\frac{T_{a}}{T_{0}}\right)\right]
$$

where:

$$
\begin{aligned}
& D_{h}=\text { hydraulic diameter of the heated zone }=\frac{4 \times \text { flow area }}{\text { wetted perimeter }} \\
& G_{h}=\text { air mass flow (flux) in heated zone } \\
& f_{h}=\text { friction factor }=0.0791 \operatorname{Re}_{h}-0.25 \\
& R_{h}=\text { Reynold's No. }=\frac{G_{h} D_{h}}{\mu} \\
& \mu \quad=\text { air dynamic viscosity }
\end{aligned}
$$

Subscript $h$ denotes heated zone

\section{B. Friction Loss in Unheated Zone (Stack)}

The air temperature is constant in this region so the

pressure loss is:

$$
\Delta P_{f s}=\frac{2 f s G_{h}^{2} L_{s}}{D_{s} D_{s}}\left(\frac{A_{f h}}{A_{f s}}\right)^{2}
$$

where:

$$
\begin{aligned}
& D_{S}=\text { hydraulic diameter of stack } \\
& \rho_{S}=\text { air density in stack }
\end{aligned}
$$


$A_{f h}=f l o w$ area in heated zone

$A_{f s}=$ flow area in stack

$f_{S}=$ friction factor in stack $=0.0791 \operatorname{Re}_{S}-0.25$

$R e_{S}=$ Reynold's No. in the stack

Subscript s denotes region above heated zone

\section{Acceleration Pressure Loss}

To determine the acceleration pressure loss, $\triangle \mathrm{Pa}$, it is convenient to use a control volume that moves with the flow (Eulerian coordinates) thereby ensuring that the same body of fluid particles are preserved in momentum calculations. Consider the following sketch:

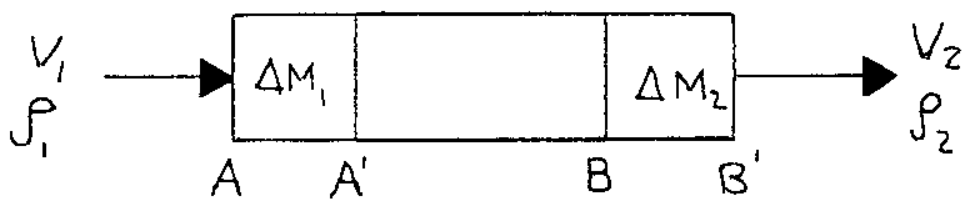

At time $t$ the vertical surfaces of the control volume lie at locations $A$ and $B$. In an added incremental time $\Delta t$ the surfaces move to $A^{\prime}$ and $B^{\prime}$ respectively. For steady flow, the small masses of fluid between $A$ and $A^{\prime}$, and $B$ and $B^{\prime}$ are respectively:

$$
\begin{aligned}
& \Delta m_{1}=\rho_{1} V_{1} A_{F} \Delta t ; \text { where } A_{F}=\begin{array}{l}
\text { area of the control volume } \\
\text { normal to the flow }
\end{array} \\
& \Delta m_{2}=\rho_{2} V_{2} A_{F} \Delta t
\end{aligned}
$$

but since, $\rho_{1} V_{1}=\rho_{2} V_{2} ; \Delta m_{1}=\Delta_{m 2}=\Delta m$ and; $\Delta m=\dot{m} \Delta t$, where 1 is the mass flow rate. Thus, in time $\Delta t$ there is a momentum loss from the control volume of magnitude $\dot{m} \Delta V_{1}$ at the inlet and a gain of, $\dot{m} \Delta V_{2}$ at the exit. The net change; m $\Delta t\left(V_{2}-V_{1}\right)=F \Delta t$, where Fut is the net impulse applied to the mass of fluid. We then have:

$$
\frac{F}{A_{F}}=\Delta P a=G\left(V_{2}-V_{1}\right)=G\left(\frac{G}{\rho_{2}}-\frac{G}{\rho_{1}}\right)
$$


or:

$$
\Delta P_{\mathrm{a}}=G^{2}\left(\frac{1}{\rho_{2}}-\frac{1}{\rho_{1}}\right)
$$

Thus for the heated zone:

$$
\Delta P_{a}=G_{h}^{2}\left(\frac{1}{\rho_{s}}-\frac{1}{\rho_{0}}\right)
$$

\section{Form Losses}

System pressure losses due to expansions, contractions, bends, etc. may be expressed as:

$$
\Delta P_{K}=k_{\text {loss }, i} \frac{\rho_{i} u_{i}{ }^{2}}{2}
$$

where the subscript $i$ denotes local geometric conditions in the system and Kloss, $i$ is a constant whose value is appropriate for the geometric change. Referred to the heated zone flow the above equation becomes:

$$
\Delta P_{K}=K_{\text {loss }, i} \frac{\rho_{i} u_{h}^{2}}{2}\left(\frac{A_{f h}}{A_{f i}}\right)^{2}=K_{\text {loss }, i} \frac{\rho_{i} G^{2}}{2 \rho_{o}{ }^{2}}\left(\frac{A_{f h}}{A_{f i}}\right)^{2}
$$

Re-defining the form loss constant as:

$$
k_{\text {loss }}=k_{\text {loss, } i}\left(\frac{A_{f h}}{A_{f i}}\right)^{2}
$$

Then:

$$
\Delta P_{\text {loss }}=K_{\text {loss }} \frac{\rho_{i} G^{2}}{2 \rho_{0}^{2}}
$$

Sunming the system pressure losses we have: 


$$
\begin{aligned}
\Sigma \text { losses } & =\frac{G^{2}}{2 \rho_{0}}\left\{\frac{\rho_{i}}{\rho_{0}} k_{\text {loss }}+\frac{2 f h^{L} h}{D_{h}}\left\{\frac{a}{T_{0}}+1\right]\right. \\
& \left.+\frac{4 \rho_{o} f_{s} L_{s}}{\rho_{s} D_{s}}\left(\frac{A_{f h}}{A_{f s}}\right)^{2}+2\left[\frac{a}{T_{0}}-1\right]\right\}
\end{aligned}
$$

For steady flow the sum of system pressure losses must equal the net thermal driving head whereby we equate Eq. (1) to Eq. (8). The resulting equation is solved by iteration to find converged values of $G$, Reynolds Nos., friction factors, convective heat transfer coefficient, average air density, and exit air temperature. The thermal analysis then proceeds as before to determine temperature of the guard vessel and duct wall simulators.

\subsubsection{Calculated RVACS Test Assembly Performance}

The foregoing equations were incorporated in the previous model of Ref. [1] and the resulting FORTRAN program is Tisted in Appendix $I$. The code was then used to calculate system performance based upon current design parameters for the simulation of PRISM. Table IV presents the important dimensions and other parameters used in the calculations. As indicated, the overall system loss coefficient was treated as a parameter. Table $\checkmark$ delineates the estimated system losses in a "wide open" configuration and Table VI shows the basis for using a loss coefficient of 1.0 for an ELGO weather cap which has been selected to cover the stack.

Figure 13 depicts a system performance map in terms of Reynold's numbers and air temperatures vs. heater input power (flux) for the range of loss coefficients assumed. These results show the deleterious effects of high form losses; however, even for the high loss cases, Reynold's numbers indicating turbulent flow are predicted and air exit temperature levels do not exceed the system limit of $300^{\circ} \mathrm{F}$, even at maximum heater power $\left(2 \mathrm{~kW} / \mathrm{ft}^{2}\right)$. With an estimated overall loss coefficient of $\sim 1.5$ for the test assembly in the "wide open" configuration, Reynoid's numbers $>1.0 \times 10^{5}$ should be easily achievable even at relatively low heater power levels. The map also indicates turbulent flow even for high losses and low heater power. 


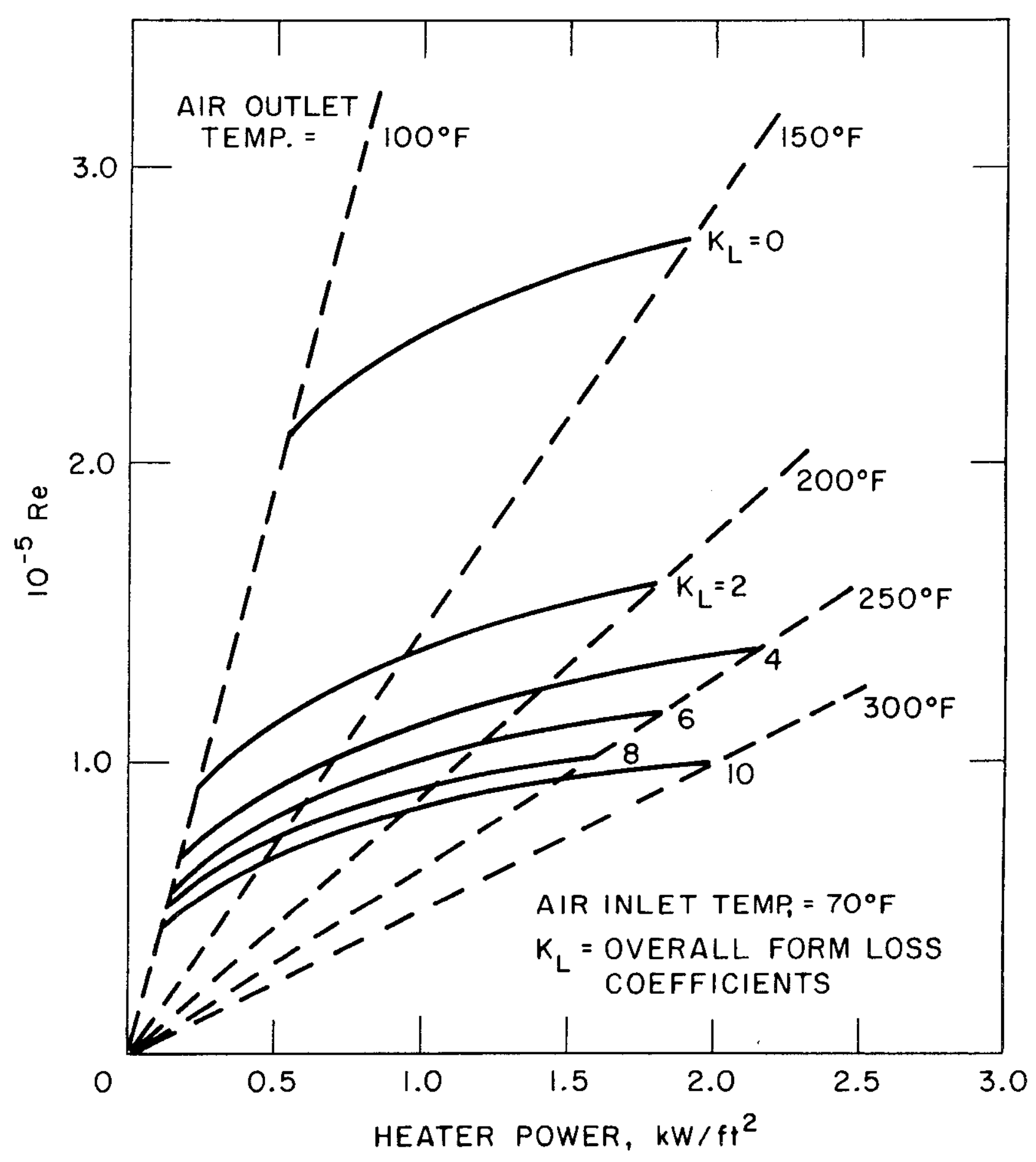

Figure 13. Test Assembly Performance Map 
Table IV. RVACS Test Assembiy Parameters

Heated length $=22 \mathrm{ft}$.

Stack height $=50 \mathrm{ft}$.

Heated channel cross section $=12^{\prime \prime} \times 52^{\prime \prime}$.

Stack channe 1 cross section $=18^{\prime \prime} \times 52^{\prime \prime}$.

Emissivity of surfaces $=0.7$.

Inlet air temperature $=70^{\circ} \mathrm{F}$.

Inlet air density $=0.0748 \mathrm{1b} / \mathrm{ft}^{3}$.

Overall KLos (Referred to inlet) $=0$ to 10 . 
Table V. RVACS LosS Coefficients for GE Simulation

\begin{tabular}{|c|c|c|c|}
\hline & & Local & Inlet \\
\hline 1. & $\begin{array}{l}\text { Entrance } \\
\text { (Re-entrant) }\end{array}$ & 0.85 & 0.85 \\
\hline 2. & $\begin{array}{l}\text { Heated zone to stack } \\
\text { transition }\end{array}$ & 0.11 & 0.11 \\
\hline $\begin{array}{ll}3 . \star & S- \\
H & \\
R & \\
2 & \end{array}$ & $\begin{array}{l}S-f \text { lue } \\
H / W \cong 3.0 \\
R / W=2.0 \\
2-60^{\circ} \text { bends }\left(0.67 \text { of } 90^{\circ} \text { ea. }\right)\end{array}$ & 0.15 & 0.067 \\
\hline \multirow[t]{2}{*}{4.} & Weather Cap & & \\
\hline & ELGO or none & 1.0 & 0.44 \\
\hline \multicolumn{2}{|c|}{ 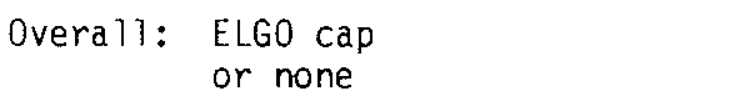 } & 2.11 & 1.467 \\
\hline
\end{tabular}


Table VI. Estimated Loss Coefficient for ELGO Weather Cap

$\Delta p=K_{\rho_{\text {air }}} \frac{u^{2}}{2}=\rho_{\mathrm{H}_{2}} \mathrm{O} \cdot g \cdot h$

$K=\frac{2 \rho_{H_{2}} 0}{\rho_{\text {air }}} \cdot \frac{g \cdot h}{u^{2}}$

$$
\begin{aligned}
& \rho_{\mathrm{H}_{2} \mathrm{O}}=997 \mathrm{~kg} / \mathrm{m}^{3} \\
& \rho_{\text {air }}=1.0 \mathrm{~kg} / \mathrm{m}^{3} \\
& \mathrm{~g}=9.8 \mathrm{~m} / \mathrm{s}^{2} \\
& \mathrm{~h}=\text { pressure loss }- \text { in } / \mathrm{H}_{2} \mathrm{O} \\
& \mathrm{u}=\text { air exhaust velocity }-\mathrm{ft} / \mathrm{min}
\end{aligned}
$$

\begin{tabular}{|c|c|c|c|}
\hline$u^{\star}$ & $u^{2}$ & $h^{\star}$ & $1.923 \times 10^{7} \mathrm{~h}$ \\
\hline 300 & $9 \times 10^{4}$ & 0.002 & 0.427 \\
\hline 400 & $1.6 \times 10^{5}$ & 0.004 & 0.481 \\
\hline 500 & $2.5 \times 10^{5}$ & 0.007 & 0.538 \\
\hline 600 & $3.6 \times 10^{5}$ & 0.011 & 0.588 \\
\hline 700 & $4.9 \times 10^{5}$ & 0.017 & 0.667 \\
\hline 800 & $6.4 \times 10^{5}$ & 0.025 & 0.751 \\
\hline 900 & $8.1 \times 10^{5}$ & 0.035 & 0.831 \\
\hline 1000 & $1 \times 10^{6}$ & 0.045 & 0.865 \\
\hline 1100 & $1.21 \times 10^{6}$ & 0.057 & 0.906 \\
\hline 1200 & $1.44 \times 10^{6}$ & 0.069 & 0.921 \\
\hline
\end{tabular}

$K=\frac{2 \times 997 \times 9.8 \times(1 / 12) \times 0.3048}{1.0 \times\left(\frac{.3048}{60}\right)^{2}} \cdot \frac{h}{u^{2}}$

$k=1.923 \times 10^{7} \frac{h}{u^{2}}$

*Values of $u$ and $h$ are taken from ELGO data. 
This is further illustrated in Fig. 14 which again indicates satisfactory system performance for a wide range of loss coefficients. These results were developed for the condition of the guard vessel temperature held constant at $900^{\circ} \mathrm{F}$.

Additional parametric calculations were made to determine other system responses, particularly wall temperatures, to variations in loss coefficients, emissivities and heater power levels. Results of these calculations are shown in Table VII. Once again the predicted air exit temperatures are a 11 we 11 within the $300^{\circ} \mathrm{F}$ limit. However, a few cases that assume high losses and/or high heater power levels, lead to high guard vessel and duct wall temperatures; e.g. guard vessel temperatures well above $1000^{\circ} \mathrm{F}$. This will also be an initial system operating limit; therefore such cases, which may challenge system integrity will be avoided, at least in early tests.

An additional set of calculations were made to investigate the size of the guard vessel to duct wall gap on system performance. Previous calculations led to a conclusion [Ref. 1] that the gap size only weakly affected the system. This conclusion is now considered erroneous because it was based on the assumption of low exit/entrance pressure losses, i.e., a value of $\Omega$ in the range of 0.5 was used which is equivalent to assuming that the pressure loss in the heated zone represents about half the total system pressure drop. This is equivalent to overall entrance/exit loss coefficients of small fractional values (see Appendix I of Ref. [1]).

Now realizing that system pressure losses are dominated by form losses, the effect of gap size on system performance was re-calculated leading to a much different conclusion regarding its effect. This is demonstrated in Figures 15 to 17 . Figure 15 shows the temperature lowering potential afforded by reduction in gap size when any appreciable entrance/exit pressure losses exist in the system. The lower curve is unachievable but shown to indicate the basis of the previous conclusion of low system sensitivity to gap size when losses are small. The other, more reasonable curves, show temperature reductions on the order of $300^{\circ} \mathrm{F}$ may be achieved by gap size reduction from the current value of 12 inches to $\sim 5$ to 6 inches. Although the curves show minima in the 3 to 4 inch range, such small gaps may be infeasible for reactor construction. 


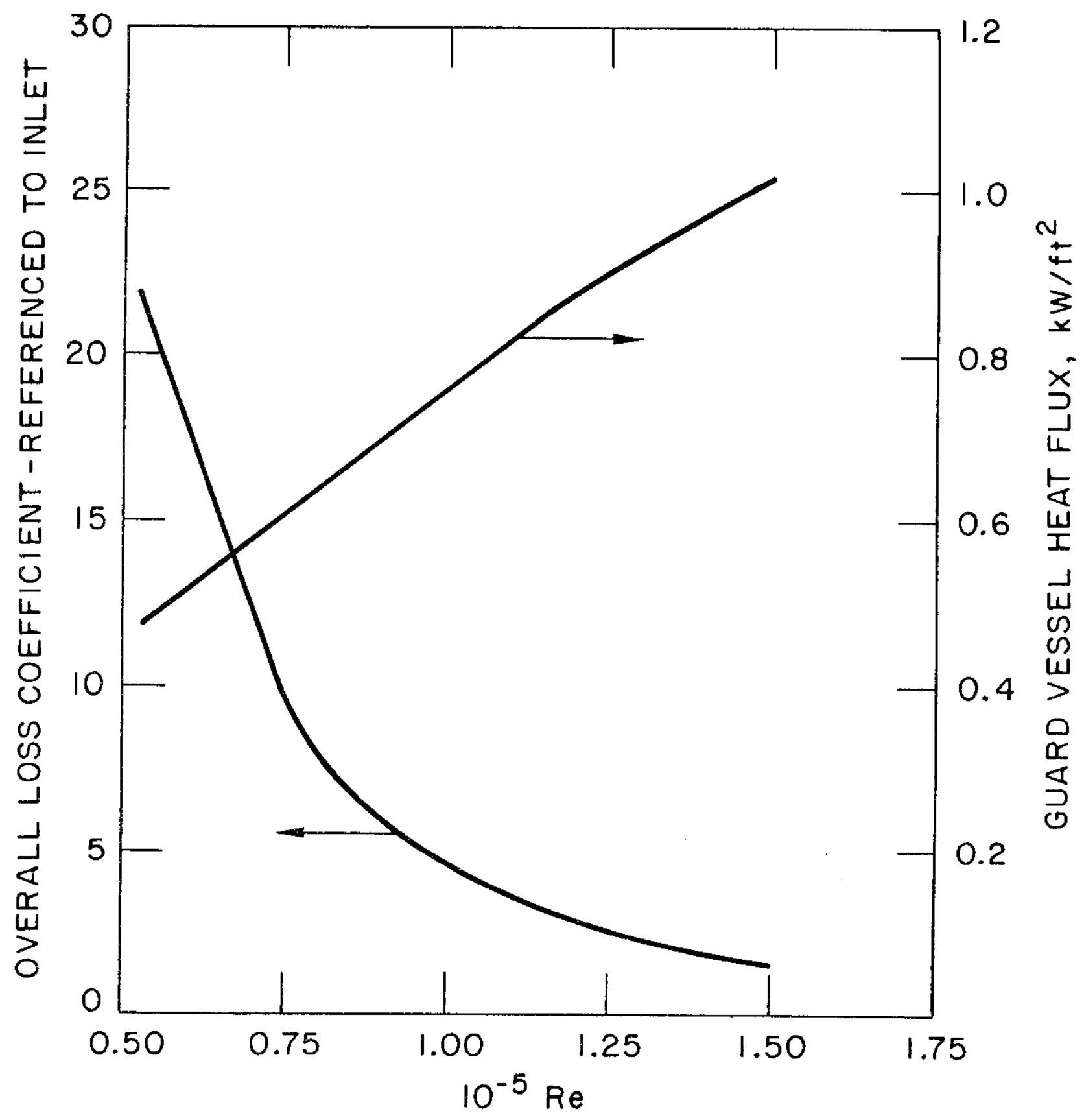

Figure 14. Performance for Guard Vessel Temperature $=900^{\circ} \mathrm{F}$ 


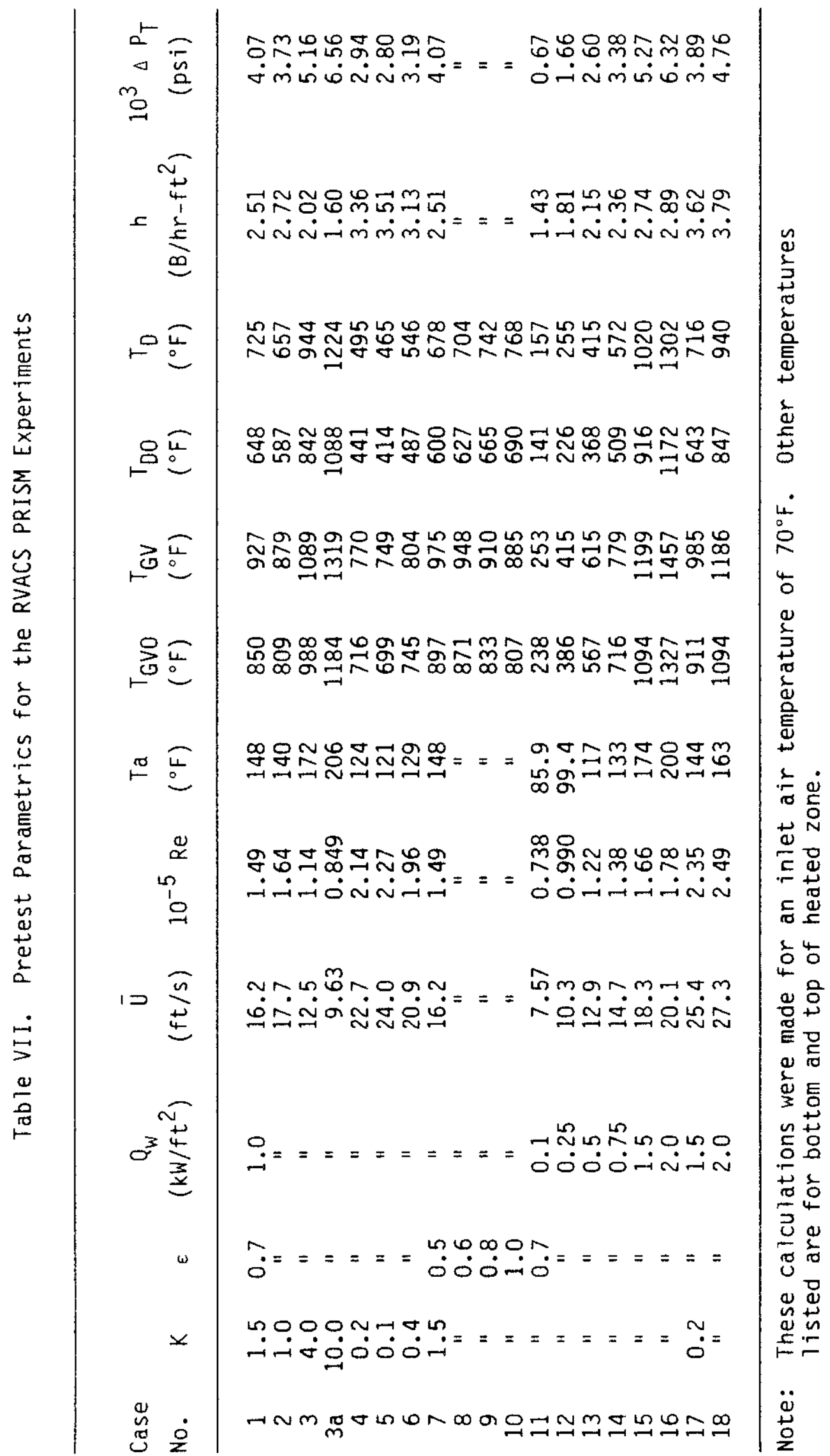




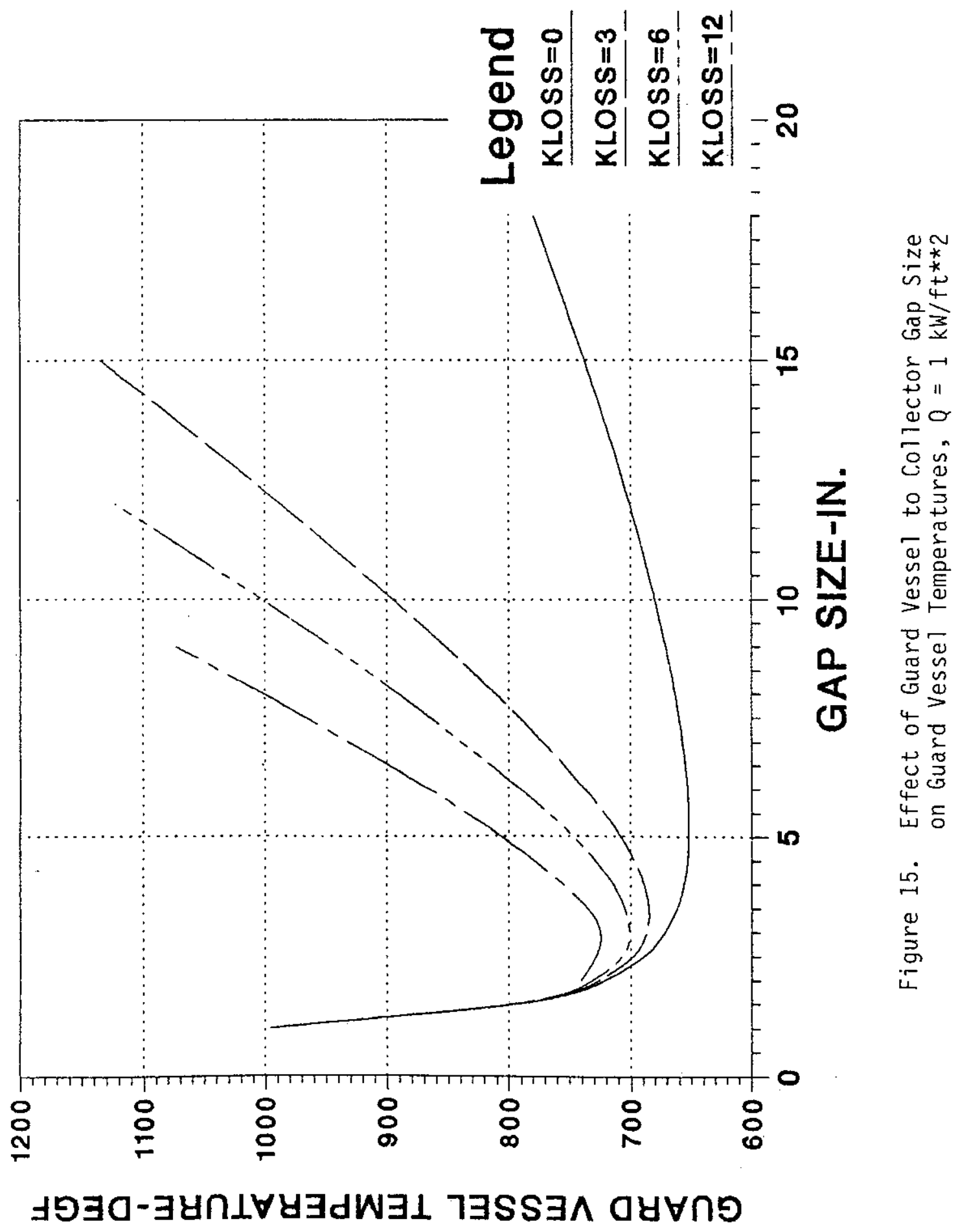




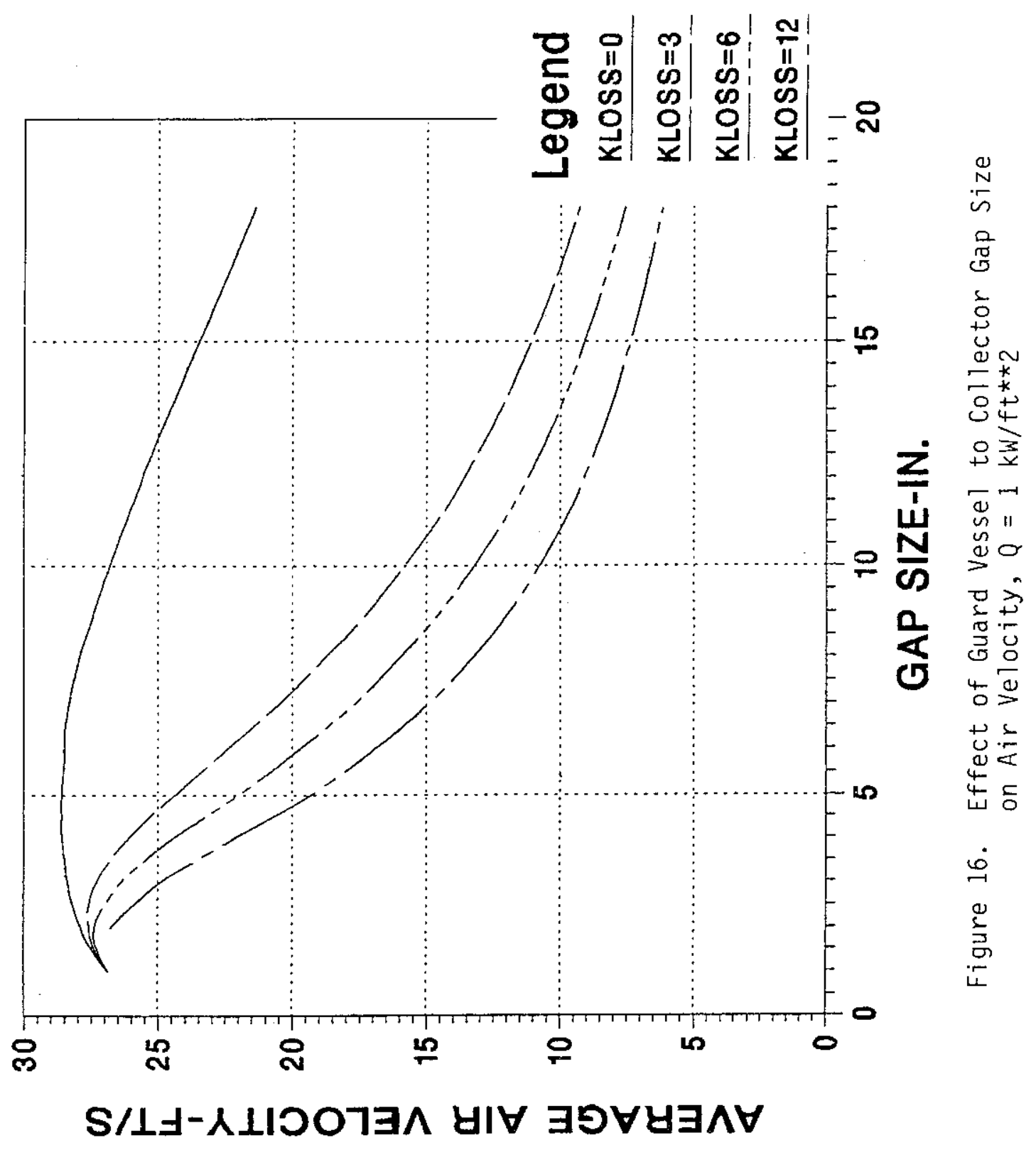




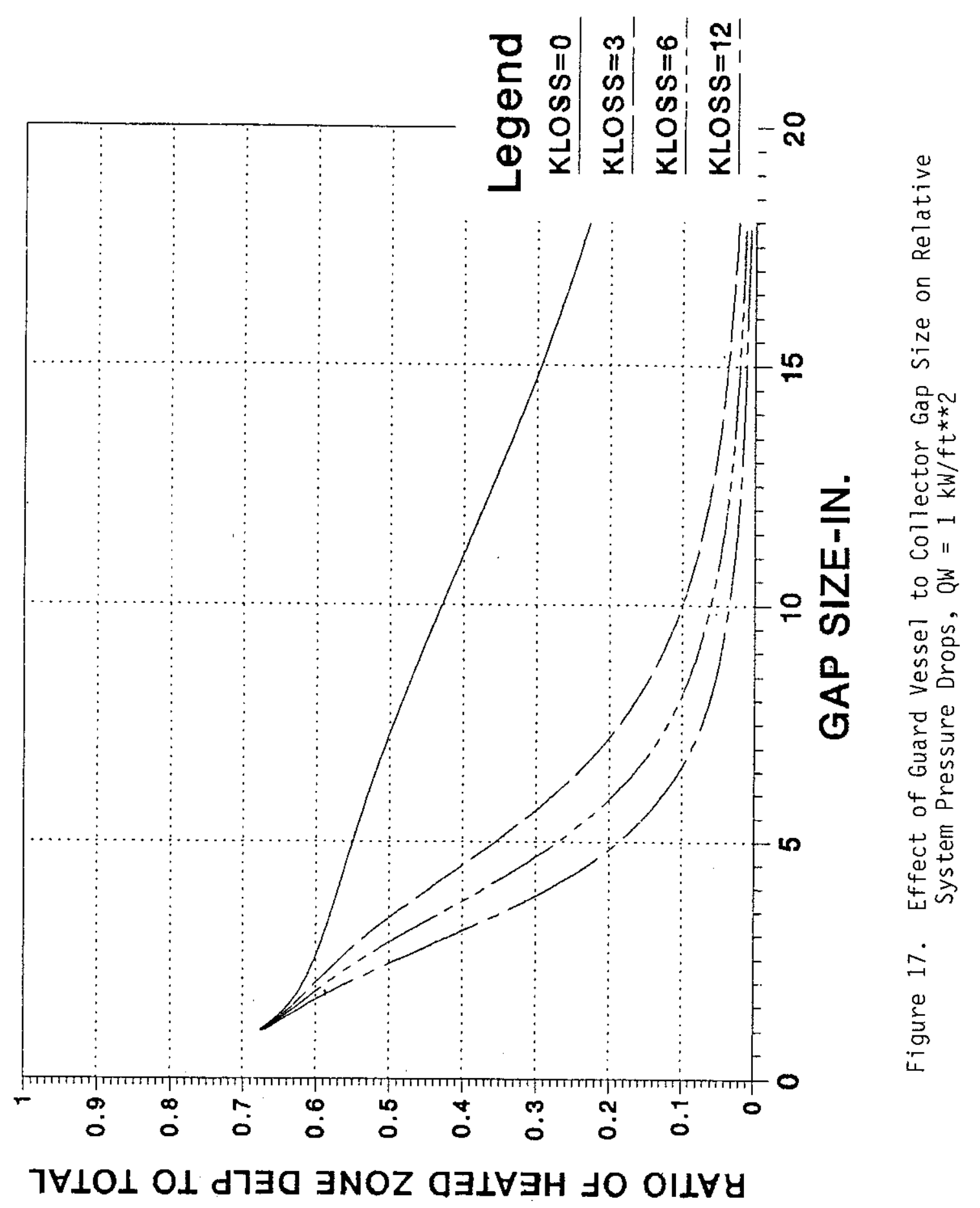


The temperature drop with initial gap size reduction occurs because until the friction loss in the heated zone becomes significant, the mass flow rate tends to remain essentially constant. This causes the velocity to increase thereby increasing the heat transfer coefficient and concommitant heat removal at lower $\Delta T^{\prime} s$.

The velocity response to gap reduction is depicted in Fig. 16; it turns over at the points of temperature minima.

Finally Fig. 17 shows relative pressure drop in the heated zone. This clearly shows the dominance of the entrance/exit losses at the larger gap sizes.

Therefore, the previous conclusion on the insensitivity of the system to gap size is reversed. These current results indicate that a potential for considerable improvement in performance can be achieved with a reduced gap size.

\subsection{COMMIX-1A Analys is}

\section{RVACS Turbulence Modeling Us ing COMMIX-1A}

The design and licensing of a RVACS system will require a detailed understanding of the air-side performance of the natural convecting air stream including such uncertainties as variation in the circumferential variations in the gap between the guard vessel and collector, partially blocked entrances, etc. The purpose of this analysis is to make use of the data obtained in the RVACS experiment to validate COMMIX as a useful tool in the prediction of airside-velocities and heat transfer coefficients.

COMMIX-1A provides two turbulence models, viz. a constant turbulence model and a one-equation ( $k$ ) model. Both have been tried in simple representations of the heated zone of RVACS; results have been unsatisfactory for both methods. 
Increasing the molecular viscosity of air to simulate the effect of turbulence and then providing such a value as input to COMMIX for the constant viscosity model simply does only that, i.e., it makes the fluid more viscous but does not treat the turbulent eddy diffisuivity. Thus, a turbulent flow pattern does not develop and the flow profile across the channel is characteristic of laminar flow. An example is shown in Fig. 18 where the channel exit flow is shown for isothermal conditions with the normal molecular viscosity of the air increased by a factor of 100 . The parabolic shape indicates laminar flow.

Calculations were then made using the one-equation turbulence option ( $k$ model) available in COMMIX-1A. These results, using default values of adjustable parameters showed the calculated turbulent intensities to be too high. The wall stress was excessive as evidenced by the high pressure drop through the system. Changing parameters in the near-wall model reduced the pressure drop to a value reasonably close to that prediced by a lumped parameter model using a friction factor for fully developed turbulent flow. It was hoped that this change would favorably resolve other calculated quantities, e.g., turbulent kinetic energy magnitude and shape, velocity profiles and magnitude of turbulent viscosity. However, such was not the case and a literature search was then made to find target values of these quantities to be used in further calibration runs. The best data for RVACS calculations to be checked against was found in [2]. This study included both symmetric and asymmetric heating of two channel walls with the latter condition representative of RVACS operation.

Our initial calculations with the one equation model were for the simplest case, i.e., for isothermal conditions. Then target curves were those shown in Fig. 19 (velocity profiles) and Fig. 20 (turbulent kinetic energy) for Grasshof No. $=0.0$. Leaving the near-wall adjustable constants as previously determined, a large number of parametric runs were made adjusting remaining constants. None of these calculations provided satisfactory results. The best solutions are depicted in Figs. 21 and 22 . Comparing Fig. 22 to Fig. 20 shows the COMMIX calculation yielding turbulent kinetic energy levels approximately a factor of four greater than target values. Similarly comparison of Fig. 21 with Fig. 19 shows that COMMIX predicts a velocity profile that is much too flat. 


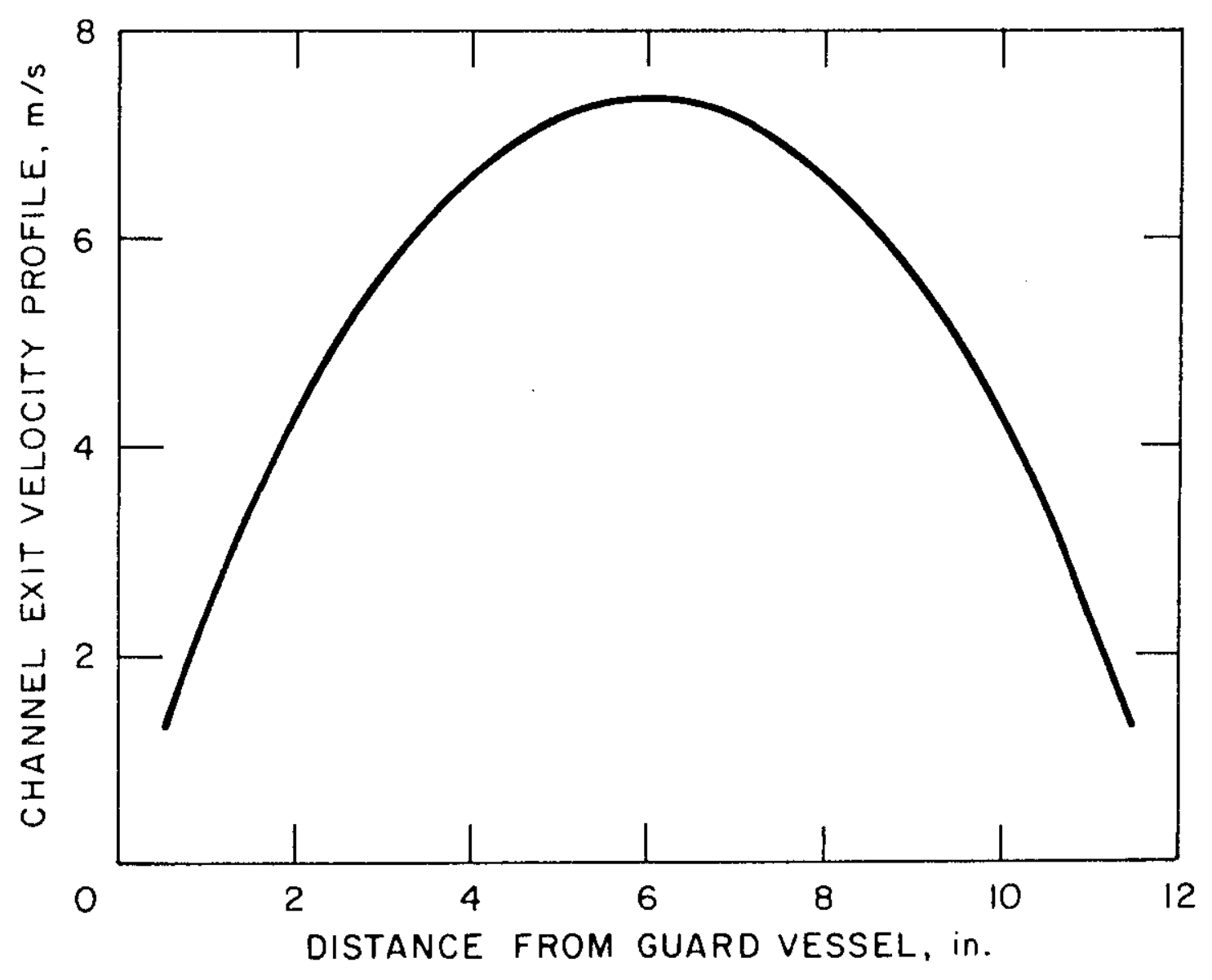

Figure 18. Air Velocity Channeling in RVACS $U=5 \mathrm{M} / \mathrm{S}$, $Q=0 \mathrm{KW} / \mathrm{M}^{\star \star 2} 2$, MUT $/ \mathrm{MU}=100$ 


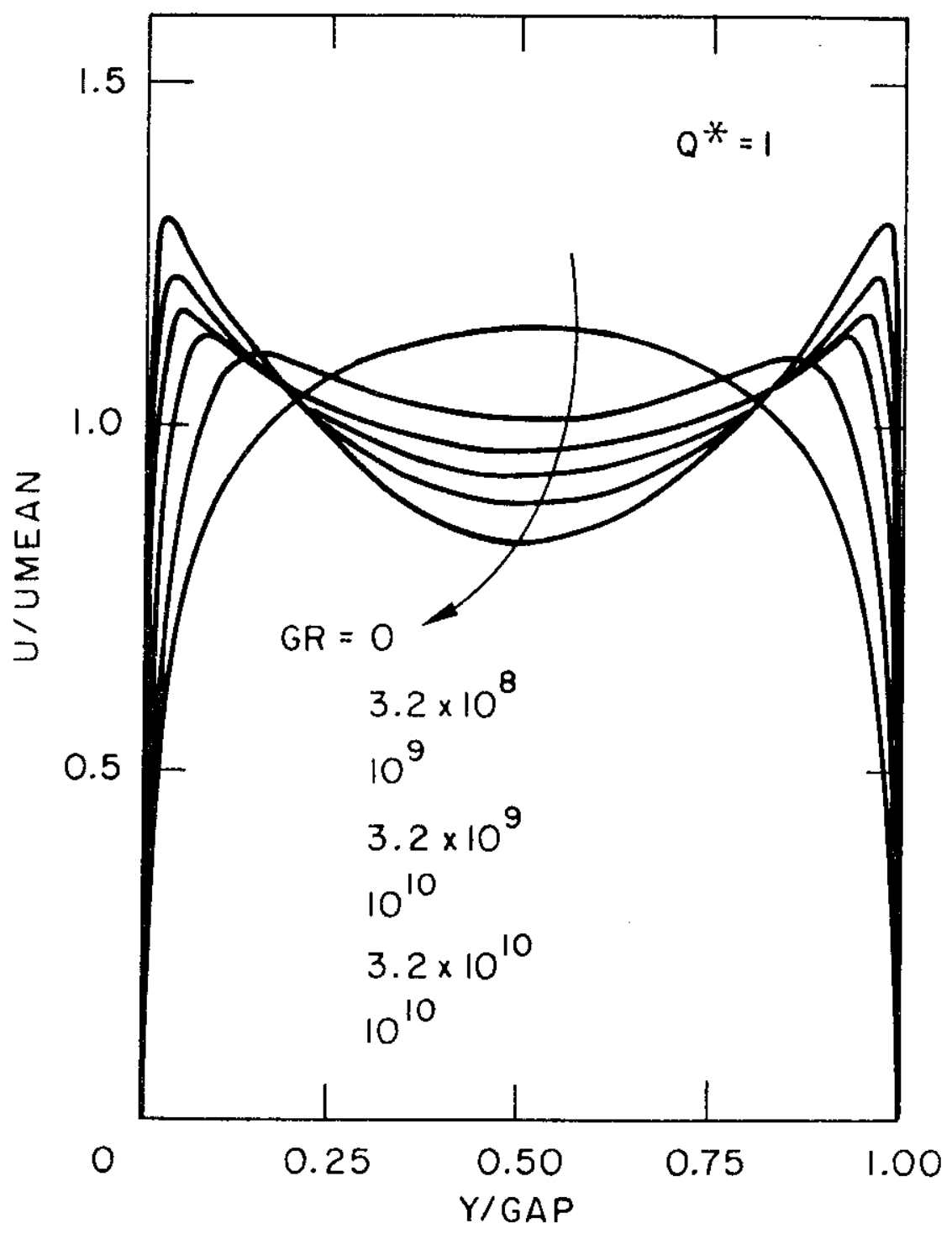

Figure 19. Velocity Profiles for Symmetric Heating 


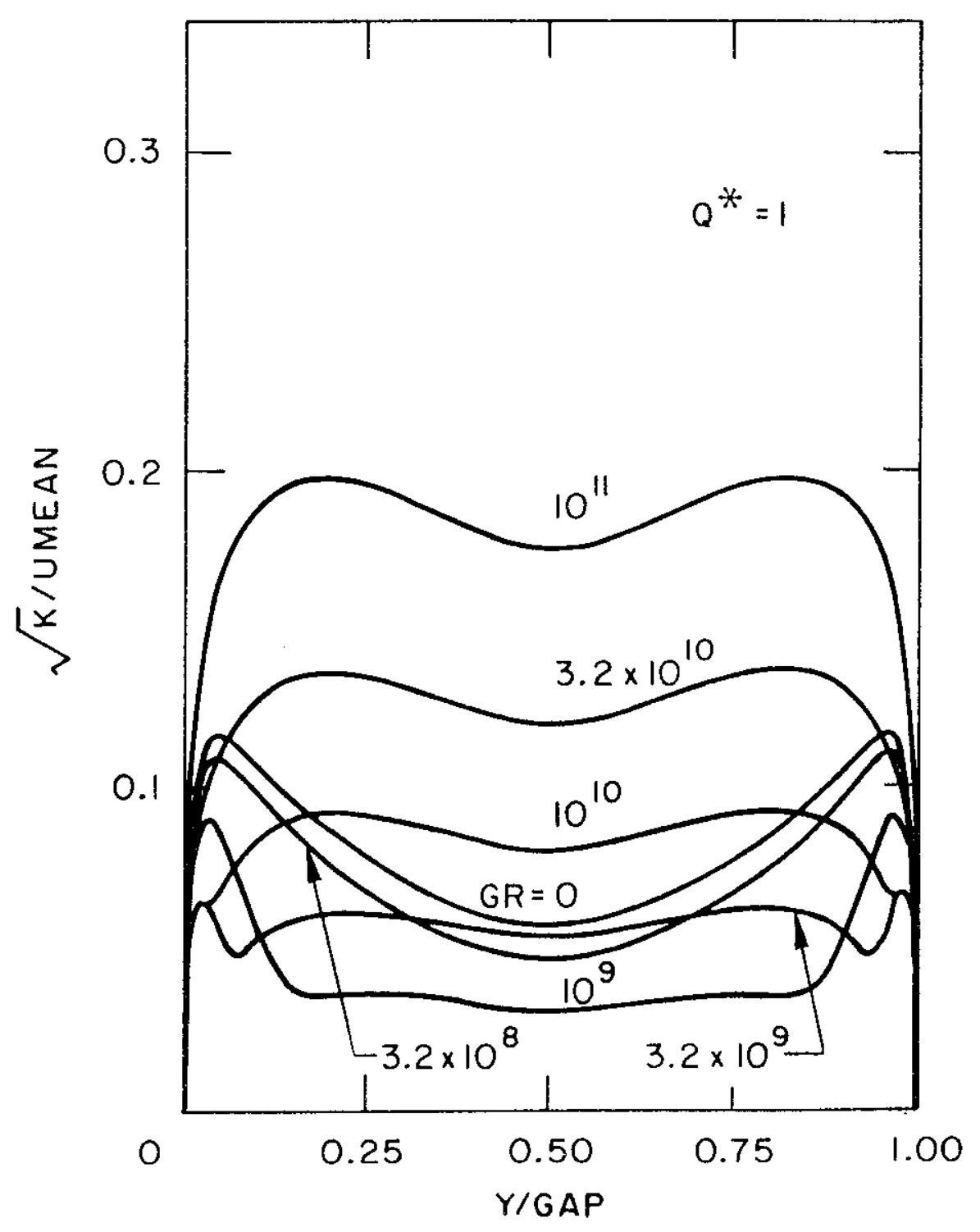

Figure 20. Turbulent Kinetic Energy for Symmetric Heating 


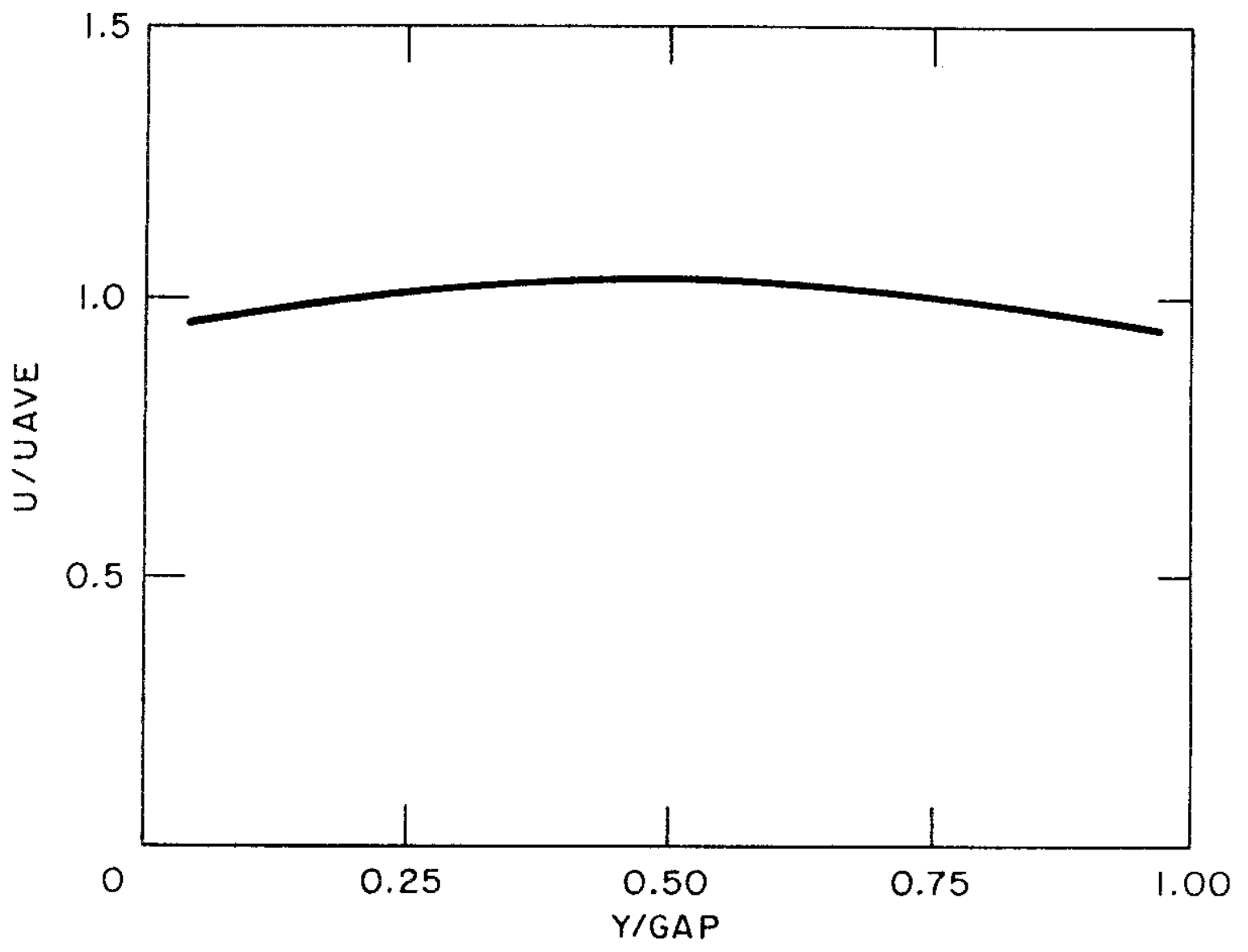

Figure 21. RVACS Velocity Profile at Exit $U=5 \mathrm{M} / \mathrm{S}$, $Q=0.0,1-E Q$ Turb. Mode 1 


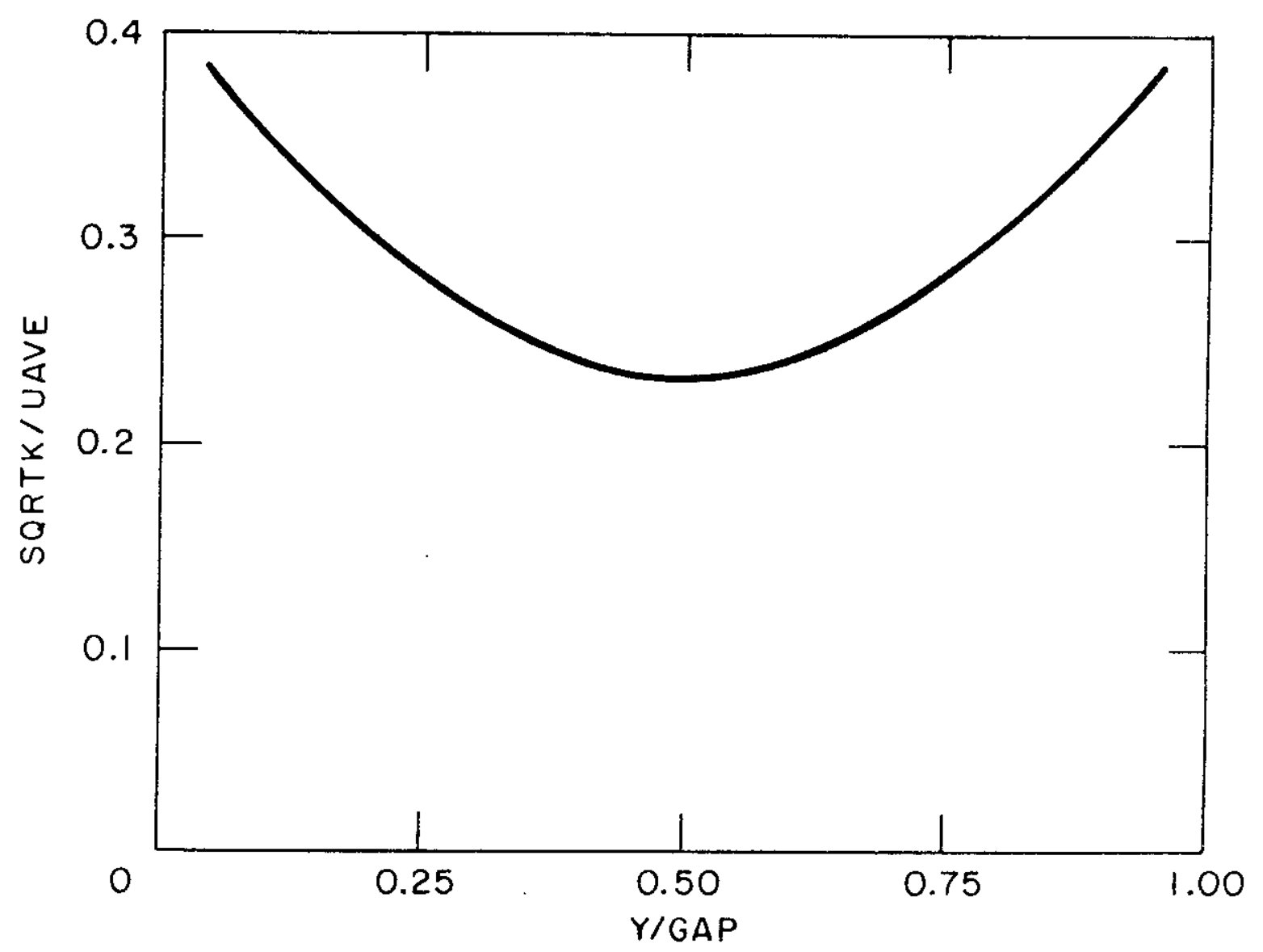

Figure 22. RVACS Turb. Kinetic Energy Profile at Exit $U=5 \mathrm{M} / \mathrm{S}, Q=0.0,1 \mathrm{EQ}$ Turb. Model 
These failures to achieve acceptable results for turbulence modeling using COMMIX-1A and the one-equation model were discussed with code developers at ANL CT Division. It was concluded that the turbulence models in COMMIX-1A were probabiy inadequate for our purposes, having been developed with emphasis on treating flow through rod bundles. We were advised that superior models are available in COMMIX-1B which contains two-equation $(k-\varepsilon)$ modeling of turbulence and that a much greater potential for acceptable results is expected with its use. Unfortunately, to date, COMMIX-1B does not treat air side radiation heat transfer. Nonetheless, current plans are to use COMMIX-1B for RVACS turbulence modeling and to simulate radiation heat transfer by other means. 


\subsection{REFERENCES}

1. T. C. Chawla, et a1., "Modeling of the Air-Side Performance of the RVACS Shutdown Heat Removal System--Status of Experimental Program," ANL-PRISM-8 (January 1986).

2. J. R. Pietrzyk and M. E. Crawford, "A Numerical Investigation of Turbulent Mixed Convection in Vertical Annular Channels," ASME, HTD-VO1. 42, Fundamentals of Forced and Mixed Convection, Eds. A. Kulacki and R. D. Boyd, 23rd National Heat Transfer Conference, Denver, Colorado (August $4-7,1985$ ). 
APPENDIX I

This appendix presents a FORTRAN source code listing of the program used to obtain the results presented in Section 2 of this report.

FILE: SMOOTHBR FORTRAN A1 ANLVM VM/SP 405 CMS

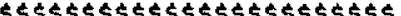

$5 M 000020$

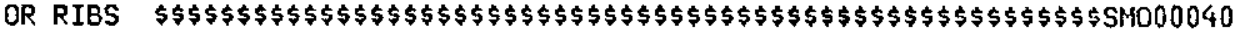

54000050

SM000060

THIS PROGRAM IS FOR SHRS WITHOUT FINS OR RIBS I.E. FOR SMOOTH Sim000070

CHANHIELS. THE BOUYANCY DRIVEN AIR FLOW IS BASED ON EQ'S. DERIVED SMO00080

BY P.A. LOTTES. REMAINING FORMULATIONS BY F.B. CHEUNG. SHO00090

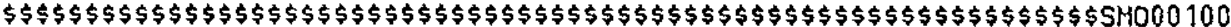

UNITS OF OUTPUTS ARE BRITISH 4-15-86

SM000110

SM000120

SM000130

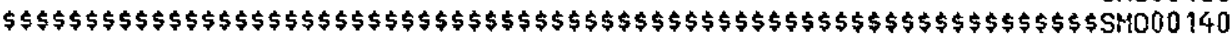

SM000150

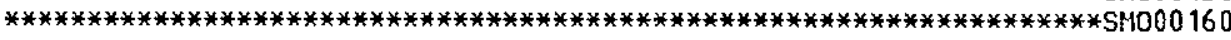

*

SM000170

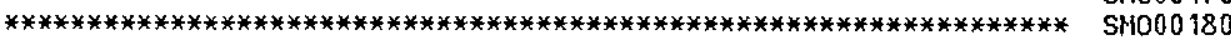

IMPLICIT REAL*8(A-H,O-Z)

REAL L,LH,MU,NU, K, LS, KLOSS, KLOSSI

DATA RHO, GRAV, BETA, TO, CP, MU, ALPHA, NU, K, SIGMA, AE, AH

SHO00190

SHO00200

SM000210

$1 / 1.200,9.8,0.00367,294.4,1 . E 3,1.83 E-5$

$2 \quad 2.25 \mathrm{E}-5,1.58 \mathrm{E}-5,0.0257,5.67 \mathrm{E}-8,1.0,1.0 /$

SH000220

SHO00230

DATA CCONV/0.01/

1 HRITE $(6,3)$

3 FORMAT ( $1 X$, 'INPUT $H, W$, HS AND WS IN INCHES')

SHO00240

$5 M 000250$

READ $(5, *) H, W, H S, W S$

HRITE $(6,4)$

4 FORMAT ( $1 X$, 'ENTER STACK HEIGHT AND HEATED LENGTH IN FEET')

SM000260

$5 M 000270$

511000280

SM0002SO

READ $(5, *)$ LS, LH

$\mathrm{LH}=0.3048 * \mathrm{LH}$

SM000300

LS $=0.3048 *$ LS

SM000310

SM000320

$\mathrm{L}=\mathrm{LS}+\mathrm{LH}$

SHO00330

WRITE $(6,5)$

51000340

5 FORMATI 1 X, 'ENTER VALUE OF KLOSSI AND EMISSIVITIES FOR RVACS \& RV' 'SMO00350

READ (5,*) KLOSSI, EPS, EPSRV $\quad$ SHO00360

$\mathrm{H}=\mathrm{H} / 39.37$

$W=W / 39.37$

HS $=$ HS $/ 39.37$

S11000370

S11000380

WS $=W S / 39.37$

AFH $=\mathrm{H} * \mathrm{~W}$

AFS $=$ HS $*$ HS

$\mathrm{DH}=4.0 * \mathrm{H} * \mathrm{H} /(2.0 *(\mathrm{~W}+\mathrm{H}))$

$D H S=4.0 * W S * H S /(2.0 *(W S+H S))$

$A F L=A F H$

KLOSS $=K L O S S I *(\{$ AFH $/ A F L) * 2) /($ RHO $* * 2)$

511000390

SHO00400

SHO00410

$5 M 000420$

Si 1000430

Sis000440

SM000450

Sit000460

$\mathrm{BRH}=\mathrm{H} * 39.37 / 12$.

SN000470

$B R W=H * 39.37 / 12$

BRHS $=H S * 39.37 / 12$.

$5 \% 1000480$

BRWS=WS $* 39.37 / 12$.

SHO00490

$B R L S=L S / 0.3048$

SH000500

$B R L H=L H / 0.3048$

SM000510

BRAFH $=A F H /(0.3048 * * 2)$

BRAFS $=A F S /(0.3048 * * 2)$

S4000520

$B R D H=D H /(0.3048)$

S1000530

SM000540

SM000550 
FILE: SMOOTHBR FORTRAN A1 ANLVM VM/SP 405 CMS

BRDHS=DHS $/(0.3048)$

SM000560

HRITE $(6,6) \mathrm{BRH}, \mathrm{BRLH}, \mathrm{BRLS}, \mathrm{KLOSSI}, \mathrm{EPS}$, EPSRV, BRW, BRDH, BRHS, BRWS , BRDHSSMO00570 $>$, BRAFH, BRAFS

WRITE $(50,6)$ BRH, BRLH, BRLS, KLOSSI, EPS, EPSRV, BRH, BRDH, BRHS, BRWS,

SM000580

SHOO0590 SBROHS, BRAFH, BRAFS

6

FORMAT ( $1 X,{ }^{\prime} H={ }^{\prime}, F 10.4,2 X,{ }^{\prime} L H=', F 10.4,2 X, ' L S=', F 10.4,2 X$,

$5 M 000600$

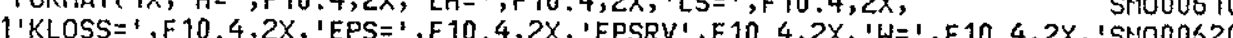

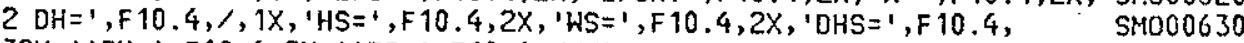

$\left.32 X,{ }^{\prime} A F H=1, F 10.4,2 X,{ }^{\prime} A F S=1, F 10.4,1 / 1\right)$

7 WRITE $(6,8)$

$\operatorname{READ}(5, *)$ QW

$Q H=1 . E 3 * Q H$

EPSW $=$ EPS

C THE FOLLOWING ASSIGNMENT OF AH=400 IS AN INITIAL GUESS

C THE FOLLOWING ASSIGNMENT OF G AND TA IS AN INITIAL GUESS

$G=1.0$

$T A=350$.

RHOBAR $=(R H O * D L O G(T A / T O)) /(T A / T O-1.0)$

RHOA $=R H O *(T O / T A)$

RHOI $=$ RHO

$11 \quad R E=G * D H / M U$

$R E S=(G * D H S / M U) *(A F H / A F S)$

C BLASIUS FRICTION FACTOR

$F=0.0791 *(R E * *(-0.25))$

$F S=0.0791 *(\operatorname{RES} * *(-0.25))$

$D P F H=F * L H *(1.0+T A / T O) /(D H * R H O)$

$D P F S=2.0 * F S * L S *(($ AFH $/ A F S) * * 2) /(R H D A * D H S)$

$D P A C=(T A / T O-1.0) / R H O$

DPFOPM $=K L O S S * R H O I / 2.0$

$H D=R H O * G R A V *((1.0-R H O B A R / R H O) * L H+(1.0-R H O A / R H O) * L S)$

WRITE $(6, *)$ RHO, GRAV, RHOBAR, LH, RHOA, LS, HD, TA

C HRITE $(50, *)$ RHO, GRAV, RHOBAR, LH, RHOA, LS,HD, TA

SUMLOS=DPFH+DPFS+DPAC+DPFORH

GNEW $=($ HD $/ S U M L O S) * * 0.5$

$T A=T O+Q W * L H /(G N E H * C P * H)$

RHOBAR $=\{$ RHO $* D L O G(T A / T O)) /(T A / T 0-1.0)$

RHOA $=$ RHO $*(T O / T A)$

C WRITE $(6, *)$ GNEW, TA, RHOBAR, RHOA

$O E L G=G N E W-G$

IF(DABS(DELG).LT.0.013 GO TO 12

$G=G+D E L G * C C O N V$

- $\quad$ C HRITE $(6, *)$ DELG, GNEW, G, CCONV

HRITE $(50, *)$ DELG, GNEW, G, CCONV

GO TO 11

12 G=GNEW

$T A=T O+Q H * L H /(G * C P * H)$

$R H O A=R H O *(T O / T A)$

RHOBAR $=($ RHO $* D L O G(T A / T O)) /(T A / T O-1.0)$

$R E=G * D H / M U$

RES $=(G * D H S / M U) *($ AFH/AFS $)$

= C BLASIUS FRICTION FACTOR

$F=0.0791 *(R E * *(-0.25))$

SM000660

SM000670

Sm000680

54000690

$5 H 000700$

$5 M 000710$

SM000720

SM000730

SHO00740

SM000750

SMO00760

SHO000770

SHOC0780

SM000790

SH000800

SMDO08 10

SN000820

SM000830

SM000840

SMO00850

SMO00860

SM000870

$\$ 4000880$

$5 M 000890$

SM000900

SMO0OS10

SHO00920

SM000930

SHo00940

SM000950

SM000960

S11000970

SM000980

SM1000S90

Si100 1000

SMOO 1010

SMO01020

SHOO 1030

SHOO 1040

SMO01050

SH001060

SMO0 1070

SM001080

SMDO 1090

SMOO 1100 
FILE: SMOOTHBR FORTRAN A1 ANLVM VMVP 405 CMS

$F S=0.0791 *(R E S * *(-0.25))$

SMO01110 HRITE $(6,9)$ RE,F, RHOBAR,RES,FS,RHOA $\quad$ SHO01120

WRITE $(50,9)$ RE, $F$, RHOBAR, RES, FS, RHOA SMO01130

9 FORMAT ( 1X, 'REYNOLDS=', F10.2,5X, 'FRIC. FACTOR=', F 10.6, 5X, 'RHOBAR=' $>, F 10.3,1$, IX, 'REYN STACK =',F10.2,5X,'FRIC F STACK=', F10.6, 1X, 'DEN $>$ STACK $=1, F 10.3\}$

DELPH $=F *(G * 2) * L H *(T A / T 0+1.0) /(\mathrm{OH} * \mathrm{RHO})$

$D E L P S=(2.0 * F S *(G * * 2) * L S /($ RHOA $* D H S)) *((A F H / A F S) * * 2)$

SMO01140

SHO0 1150

SM001160

SHo0 1170

DPACL $=(T A / T 0-1.0) *(G * * 2) / R H O$

DPKLOS $=K L O S S *(G * 2) * R H O I / 2.0$

DPLOST $=D E L P H+D E L P S+D P A C L+D P K L O S$

DPHEAD $=R H O * G R A V *((1.0-R H O B A R / R H O) * L H+(1.0-R H O A / R H O) * L S)$

DPERR =DPHEAD-DPLOST

$P R=N U / A L P H A$

C OITTUS-BOELTER CORRELATION FOR HW

$H W=(0.023 *(R E * * 0.8)) *(P R * * 0.4) * K / D H$

C CORRELATION FOR HW DERIVED FROM IUS TEST

C $\quad H H=(1.22 *(R E * * 0.457)) *(0.72 * * 0.4) * K / D H$

WESTINGHOUSE PETUHKOV CORRELATION FOR HW

$F 2=1 . /((1.82 * A L O G 10($ RE $)-1.64) * * 2)$

HMUM $=R E * P R * F 2 / 8$.

HDEN $1=P R * *(2, / 3)-$,1 .

HDEN $2=12.7 *((\mathrm{~F} 2 / 8) * * 0.5$.

$H W=(H N U M /(1.07+H D E N 2 * H D E N 1\}) * K / D H$

$H D=H W$

$B W=Q W /(G * C P * H)$

$\mathrm{BS}=\mathrm{BH}$

10

TERMY $=($ QH $+B W *(A H-T O)) / H D$

QH

TER 15 $=(A S+B S *$ LH $/ 2) * *$.

TERH $6=H D *(1.0 /$ EPSW $+1.0 /$ EPSS -1.0$)$

ASNEH $=$ TO+SIGMA* (TERM4-TERM5 )/TERM6

DELAS = ASNEH-AS

IF(DABS(DELAS).LT.0.001) 60 TO 30

$A W=A W-D E L A S * C C O N V$

C WRITE $(6, *)$ ASNEW, AS, DELAS, AH, BW

GO TO 10

30 WRITE $(6,40)$ DELAS

40 FORHAT( $1 X$, 'ERROR IH CALCULATED VALUE OF AS=', $F 10.4$ )

$T A=T O+Q H * L H /(G * C P * H)$

UAVE $=G / R H O B A R$

$T G V=A H+B W * L H$

TFS $=A S+B S * L H$

TGVBAR $=(A W+T G V) / 2.0$

EPSA $=1.0 /(2.0 / E P S R V-1.0)$

TRVBAR $=($ TGVBAR**4+GW/(SIGMA*EPSA $) * * 0.25$

TGVO $=A W$

TRVO $=($ TGVO**4+QH/(SIGMA*EPSA $) * * 0.25$

HOVRAL $=Q W /(T R V O-T O)$

TRVO=TRVO*1.8-459.69

HOVRAL $=$ HOVRAL $/ 5.678263$

SMO01180

SHOO 1190

SHDO 1200

SHo0 1210

SPO001220

$5 M 001230$

SM001240

SHO0 1250

S1\%001260

SHO0 1270

SMO01280

SHO0 1290

SMO0 1300

SMOO 1310

SMO0 1320

SMO01330

SMO01340

SM001350

SHo0 1360

SM001370

St1001380

SH00 1390

SHo0 1400

SHO01410

SMOO 1420

Sri001430

SMOO 1440

SM001450

SHOO 1460

SMO0 1470

SHOD1480

SHOO 1490

SHOO 1500

SHOO 1510

SMO0 1520

SMOO 1530

SMO0 1540

SMO0 1550

SHO0 1560

SM00 1570

SM001580

SM001590

SM001600

HRIYE $(6,43)$ TRVO, HOVRAL

SHO0 1610

WRITE $(50,43)$ TRVO, HOVRAL

SM001620

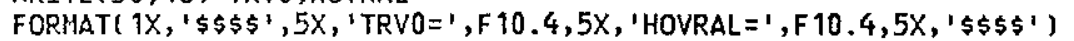

SH001630

$Q W=Q W * 1 . E-3$

$\$ 1001650$ 
FILE: SMOOTHBR FORTRAN A1 ANLVM VM/SP 405 CMS

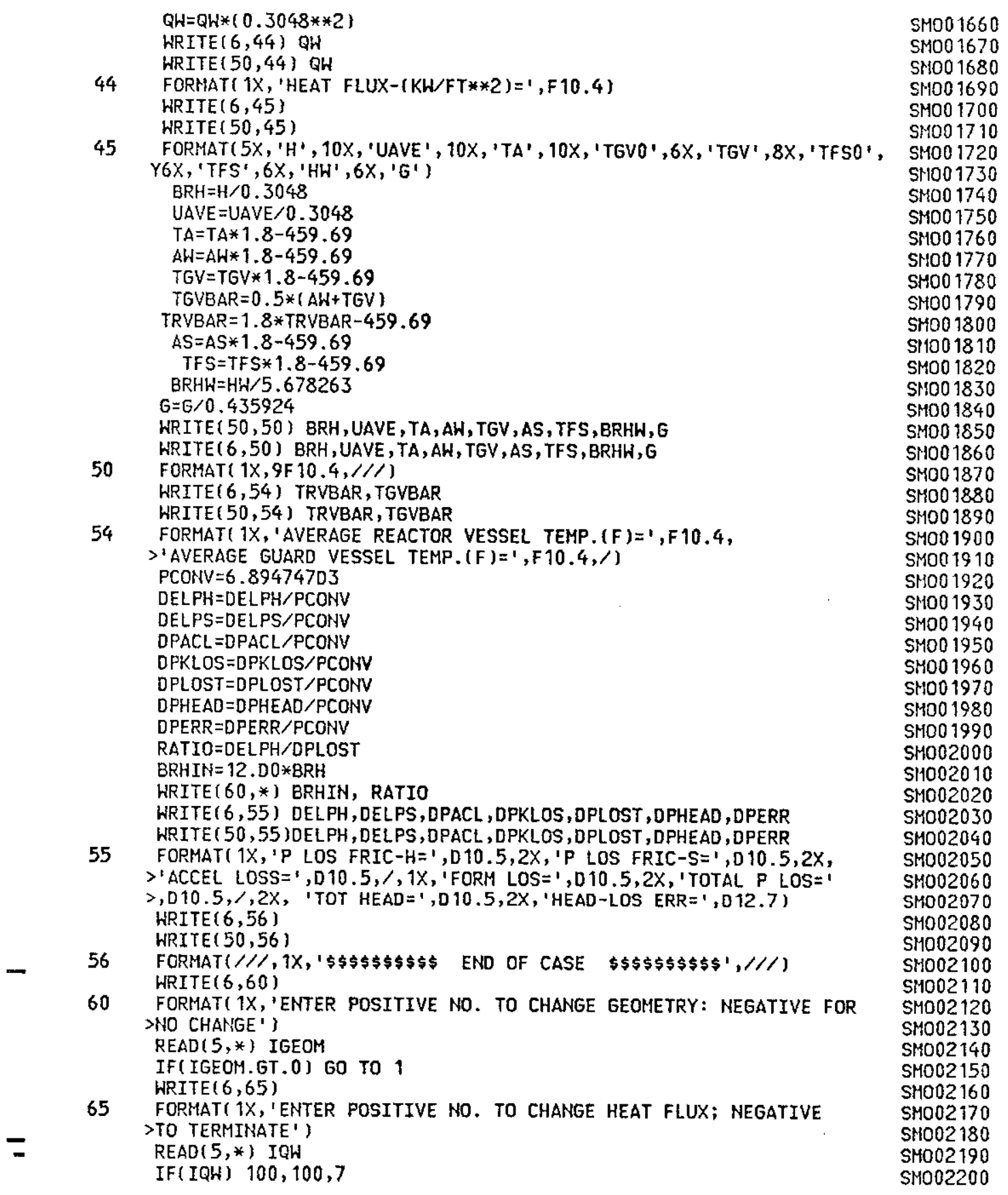


$-56-$

FILE: SHOOTHBR FORTRAN AI ANLVM VM/SP 405 CMS

100 STOP

ENSD

SM002210

SHO02220

? 